University of South Florida

DIGITAL COMMONS

Digital Commons @ University of

@ UNIVERSITY OF SOUTH FLORIDA

South Florida

3-15-1999

\title{
Western Pacific Interannual Variability Associated with the El Niño-Southern Oscillation
}

\author{
Chunzai Wang \\ University of South Florida \\ Robert $\mathrm{H}$. Weisberg \\ University of South Florida, weisberg@marine.usf.edu \\ Jyotika I. Virmani \\ University of South Florida
}

Follow this and additional works at: https://digitalcommons.usf.edu/msc_facpub

Part of the Marine Biology Commons

\section{Scholar Commons Citation}

Wang, Chunzai; Weisberg, Robert H.; and Virmani, Jyotika I., "Western Pacific Interannual Variability Associated with the El Niño-Southern Oscillation" (1999). Marine Science Faculty Publications. 124.

https://digitalcommons.usf.edu/msc_facpub/124

This Article is brought to you for free and open access by the College of Marine Science at Digital Commons @ University of South Florida. It has been accepted for inclusion in Marine Science Faculty Publications by an authorized administrator of Digital Commons @ University of South Florida. For more information, please contact digitalcommons@usf.edu. 


\title{
Western Pacific interannual variability associated with the El Niño-Southern Oscillation
}

\author{
Chunzai Wang, Robert H. Weisberg, and Jyotika I. Virmani \\ Department of Marine Science, University of South Florida, St. Petersburg
}

\begin{abstract}
Observations of sea surface temperature (SST), sea level pressure (SLP), surface wind, and outgoing longwave radiation (OLR) show that the El Niño-Southern Oscillation (ENSO) displays western Pacific anomaly patterns in addition to eastern Pacific anomaly patterns. During the warm phase of ENSO, warm SST and low SLP anomalies in the equatorial eastern Pacific and low OLR anomalies in the equatorial central Pacific are accompanied by cold SST and high SLP anomalies in the off-equatorial western Pacific and high OLR anomalies in the off-equatorial far western Pacific. Also, while the zonal wind anomalies over the equatorial central Pacific are westerly, those over the equatorial far western Pacific are easterly. The nearly out-of-phase behavior between the eastern and western tropical Pacific is also observed during the cold phase of ENSO, but with anomalies of opposite sign. These western Pacific interannual anomaly patterns are robust features of ENSO, independent of data sets. It is argued that equatorial easterly (westerly) wind anomalies over the far western Pacific during the warm (cold) phase of ENSO are initiated by off-equatorial western Pacific cold (warm) SST anomalies, and that these winds are important for the evolution of ENSO. An atmosphere model is employed to demonstrate that small off-equatorial western Pacific cold (warm) SST anomalies (compared to those in the east) are sufficient to produce equatorial easterly (westerly) wind anomalies as observed over the far western Pacific. The coupled oceanatmosphere model of Zebiak and Cane is then modified to investigate the evolution of the western Pacific interannual anomaly patterns in a coupled ocean-atmosphere system, by including a meridional structure to the subsurface temperature parameterization in the western Pacific. The modified model produces both western and eastern Pacific interannual anomaly patterns.
\end{abstract}

\section{Introduction}

Interannual climate variability associated with the El NiñoSouthern Oscillation (ENSO) has been the subject of intensive studies over the past two decades. Progress has been made in simulating the coupled tropical ocean-atmosphere system using models of varying complexity [e.g., Philander, 1990; McCreary and Anderson, 1991; Neelin et al., 1994, 1998]. The coupled ocean-atmosphere model of Zebiak and Cane [1987] (hereafter ZC) is now routinely run for ENSO forecasting. Battisti and Hirst [1989] argued that the mechanism of the ZC model is the analogical delayed oscillator of Suarez and Schopf [1988], which has both positive and negative feedbacks. The positive feedback is represented by local ocean-atmosphere coupling in the equatorial eastern Pacific. The delayed negative feedback is represented by free Rossby waves generated in the eastern Pacific that propagate to and reflect from the western boundary, returning as Kelvin waves to reverse the anomaly pattern in the eastern Pacific. Are there other mechanisms outside the eastern Pacific that may also facilitate coupled ocean-atmosphere system oscillations on interannual timescales?

Motivated by the western and west central Pacific observations presented by Mayer and Weisberg [1998] and Weisberg and Wang [1997a], Weisberg and Wang [1997b] developed a conCopyright 1999 by the American Geophysical Union.

Paper number 1998JC900090.

0148-0227/99/1998JC900090\$09.00 ceptual western Pacific oscillator model for ENSO. This western Pacific oscillator model considers the thermocline thickness in the equatorial east central Pacific, the zonal wind stress in the equatorial west central Pacific, the thermocline thickness in the off-equatorial western Pacific, and the zonal wind stress in the equatorial far western Pacific. Arguing from the vantage point of a Gill [1980] atmosphere, condensation heating due to convection in the equatorial west central Pacific [Deser and Wallace, 1990; Zebiak, 1990] induces a pair of off-equatorial cyclones with westerly wind anomalies on the equator. These equatorial westerly winds act to deepen the thermocline and increase sea surface temperature (SST) in the equatorial east central Pacific, thereby providing a positive feedback for anomaly growth. At the same time, these off-equatorial cyclones raise the off-equatorial thermocline by Ekman pumping. Thus a relatively shallow off-equatorial thermocline anomaly develops over the western Pacific, leading to a decrease in SST and an increase in sea level pressure (SLP). During the mature phase of El Niño, this off-equatorial high SLP initiates equatorial easterly winds over the far western Pacific. These equatorial easterly winds cause upwelling and cooling that proceeds eastward as a forced ocean response, providing a negative feedback for coupled ocean-atmosphere system oscillations. It is plausible that both eastern and western Pacific oscillator mechanisms may be operant in nature.

Despite the potential role of the western Pacific in ENSO, interannual variability in the western Pacific has not been well studied, probably because the SST anomalies there are smaller 

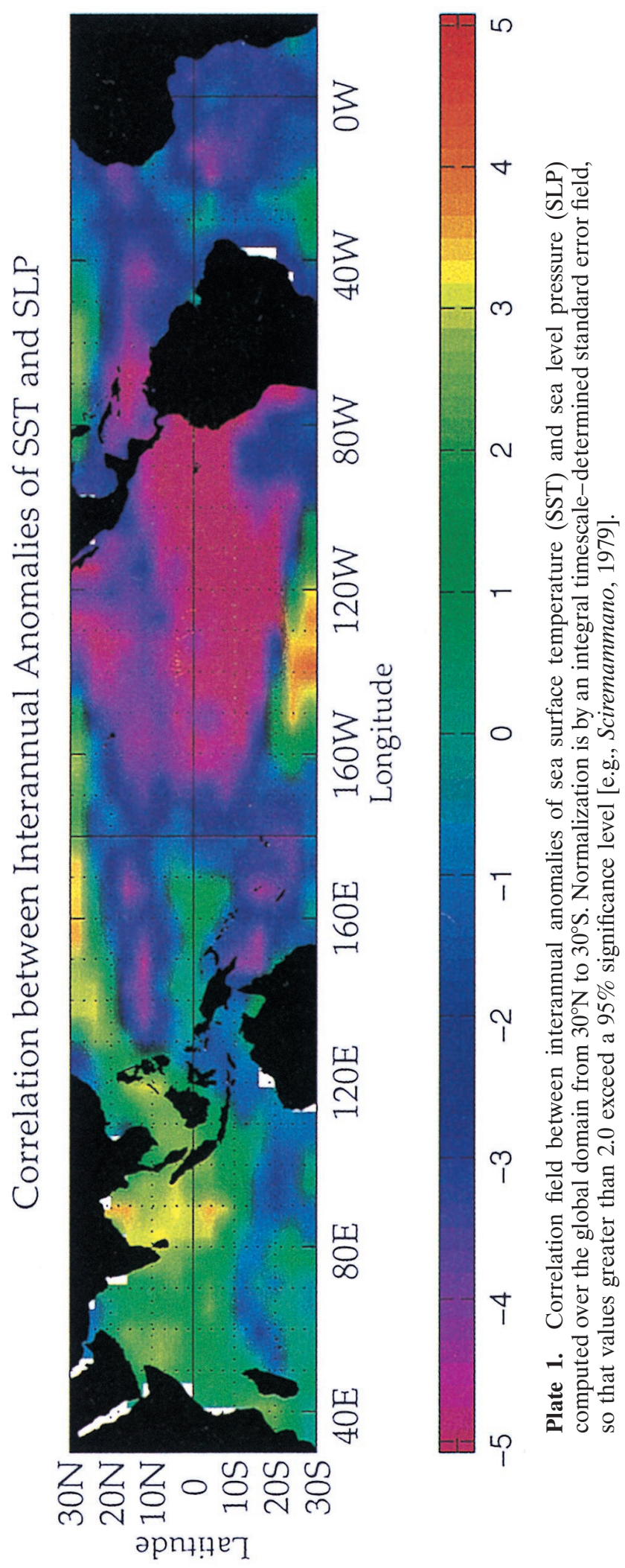

than those in the east. The present paper provides observational and numerical modeling studies of the interannual variability patterns in the western Pacific. We begin in section 2 with observations from the Comprehensive Ocean-Atmosphere Data Set (COADS) and independent outgoing longwave radiation (OLR) data that show, during the warm phase of ENSO, that equatorial eastern Pacific warm SST, low SLP, and equatorial central Pacific low OLR anomalies are accompanied by off-equatorial western Pacific cold SST, high SLP, and off-equatorial far western Pacific high OLR anomalies. These interannual anomaly patterns are associated with equatorial westerly winds in the central Pacific and equatorial easterly winds over the far western Pacific. Because of the potential importance of the western Pacific anomaly patterns, two new western Pacific ENSO indices are introduced. We then employ the atmospheric model of Zebiak [1986] in section 3 to demonstrate that small (relative to those in the equatorial eastern Pacific) off-equatorial western Pacific SST anomalies are sufficient to produce equatorial easterly winds in the far western Pacific during the warm phase of ENSO, and we provide a physical explanation for this. Section 4 then modifies the coupled ZC model to include a meridional structure to the subsurface temperature anomaly parameterization in the western Pacific. With this modification the coupled model produces off-equatorial western Pacific cold SST and equatorial easterly wind anomalies over the far western Pacific during the warm phase of ENSO. The results from 100 year integrations of the standard and modified ZC models are compared in section 5. Discussions along with a summary are provided in section 6 .

\section{Observations}

The COADS data from January 1950 to December 1992 [Woodruff et al., 1987], as used by Mayer and Weisberg [1998], and the OLR data from January 1974 to December 1992 (obtained from the National Oceanic and Atmospheric Administration (NOAA)/National Centers for Environmental Prediction (NCEP) Climate Prediction Center) are used for analyzing interannual relationships between anomalies in the eastern and western tropical Pacific. SLP and surface winds are drawn directly from the COADS. SST is from the version of the COADS data prepared by Smith et al. [1996], in which the SST field is reconstructed using a spatial interpolation method employing empirical orthogonal functions (EOF). The use of EOF basis functions produces an improved SST analysis, better representing the large-scale, sparsely sampled structures than the traditional spatial and temporal interpolation analyses (see Smith et al. [1996] for details). Both the original COADS and the Smith et al. [1996] SST data are on a $2^{\circ}$ latitude $\times 2^{\circ}$ longitude grid. These data are further averaged into $4^{\circ}$ latitude $\times 6^{\circ}$ longitude boxes. The OLR data are on a $2.5^{\circ}$ latitude $\times 2.5^{\circ}$ longitude grid. Anomalies are calculated by subtracting the monthly climatologies from the data.

Using these anomalies, fields of SST, OLR, SLP, and surface winds are developed for the warm and cold phases of ENSO. Previously, Rasmusson and Carpenter [1982] gave a comprehensive description of a composite El Niño using the surface wind and SST data from 1949 to 1976, and Rasmusson and Wallace [1983] presented OLR anomalies during the 19821983 El Niño. These studies showed some similar western Pacific features, but they were not emphasized, probably due to their relatively small magnitude when compared with the eastern Pacific patterns. However, sections 3 and 5 will show that 

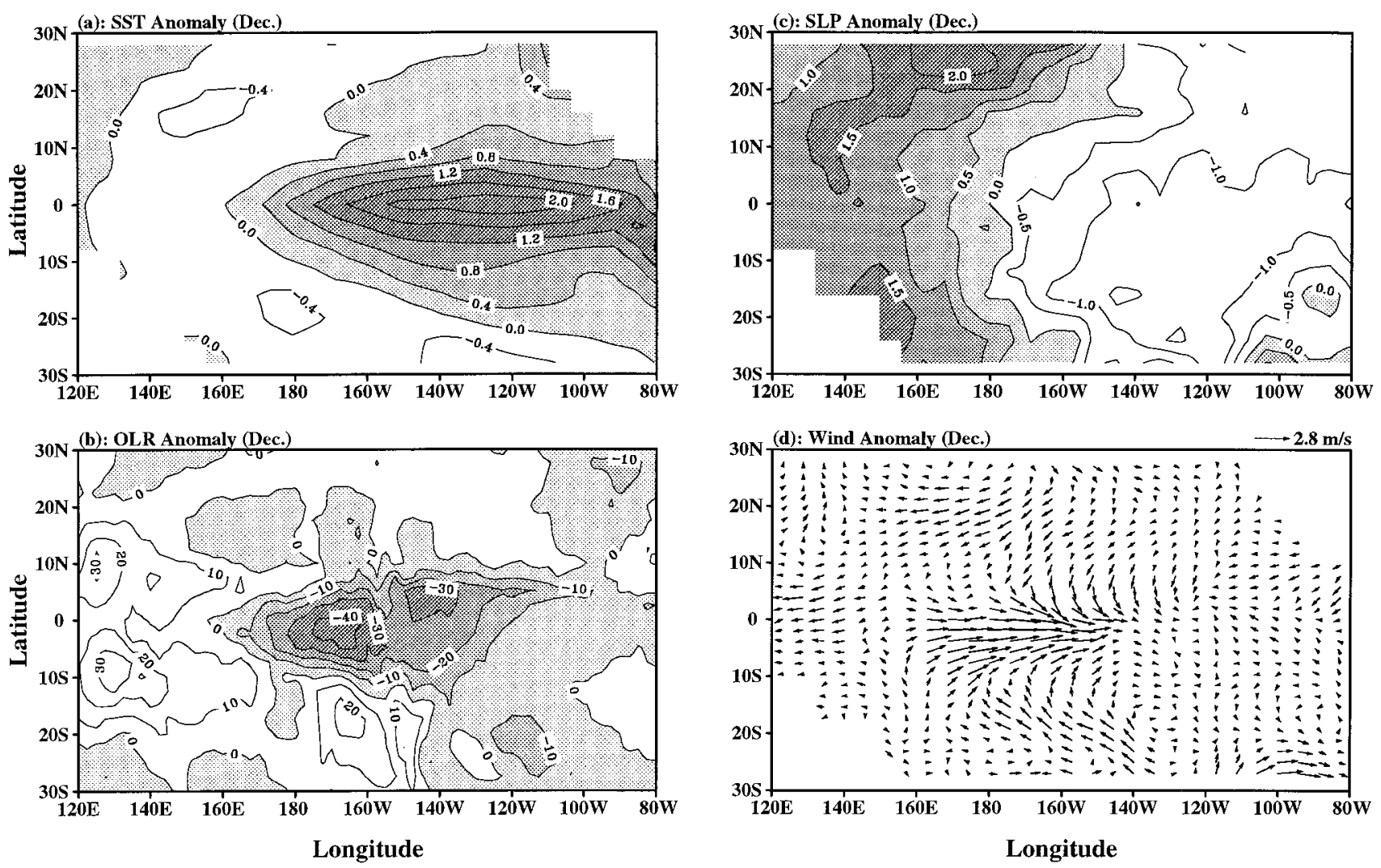

Figure 1. The horizontal structures of the tropical Pacific: (a) SST anomalies $\left({ }^{\circ} \mathrm{C}\right)$, (b) outgoing longwave radiation (OLR) anomalies ( $\mathrm{W} \mathrm{m}^{-2}$ ), (c) SLP anomalies (mbar), and (d) surface wind anomalies ( $\mathrm{m} \mathrm{s}^{-1}$ ) in December for a composite El Niño. The El Niño composite is formed by taking the average December anomaly for 1957, 1965, 1972, 1982, 1986, and 1991.

the western Pacific patterns may have important dynamical consequences.

We begin with the correlation field between the interannual anomalies of SST and SLP in the global tropics as shown in Plate 1. Distinctively different correlation patterns are observed in the eastern and western Pacific. A broad region of negative correlation is centered on and symmetric about the equator in the eastern Pacific, whereas in the western Pacific the symmetric and negative correlations located $8^{\circ}-16^{\circ}$ poleward from the equator are separated by a region of positive correlation on the equator. Thus during the warm phase of ENSO, the equatorial eastern Pacific shows warm SST anomalies accompanied by low SLP anomalies, whereas the offequatorial western Pacific shows cold SST anomalies accompanied by high SLP anomalies. The converse occurs during the cold phase of ENSO.

The basis for the statistical correlation pattern in the tropical Pacific is evident in almost every ENSO cycle observed over the period of record, either in the individual time series or the composite averages. Figures 1 and 2 show the horizontal structures of the tropical Pacific SST, OLR, SLP, and surface wind anomalies in December for composite El Niño and La Niña, respectively. The El Niño composite is formed by taking the average December anomaly for 1957, 1965, 1972, 1982, 1986, and 1991, and the La Niña composite is the average December anomaly for 1955, 1964, 1970, 1975, 1984, and 1988. During the peak of El Niño, when the warmest SST anomalies are in the equatorial eastern Pacific, the coldest SST anomalies are located to the north and south of the equator in the western
Pacific, instead of on the equator. Since atmospheric convection over the western Pacific warm pool shifts into the equatorial central Pacific during the warm phase of ENSO, the region of the lowest OLR anomalies is located to the west of the warmest SST anomalies. Like the relative position between the SST and the OLR anomalies in the equatorial eastern and central Pacific, in the western Pacific the off-equatorial region of highest OLR anomalies is positioned west of the offequatorial region of coldest SST anomalies. The off-equatorial western Pacific cold SST anomalies are also accompanied by off-equatorial western Pacific high SLP anomalies. As a result of off-equatorial high SLP, equatorially convergent winds are generated that turn anticyclonically to equatorial easterly winds over the far western Pacific, as observed in Figure 1d. Thus during the peak warm phase of ENSO, the equatorial eastern Pacific shows warm SST and low SLP anomalies, and the equatorial central Pacific shows low OLR anomalies, while the off-equatorial western Pacific shows cold SST and high SLP anomalies, and the off-equatorial far western Pacific shows high OLR anomalies. Associated with these SST, SLP, and OLR anomaly patterns are equatorial westerly wind anomalies in the central Pacific and equatorial easterly wind anomalies in the far western Pacific. The converse is seen during the cold phase of ENSO, as shown in Figure 2.

The SST and wind composites for the mature phase of ENSO of Rasmusson and Carpenter [1982] also show equatorial easterly wind anomalies over the far western Pacific associated with off-equatorial western Pacific cold SST anomalies, except with smaller off-equatorial SST anomaly amplitudes (see their 

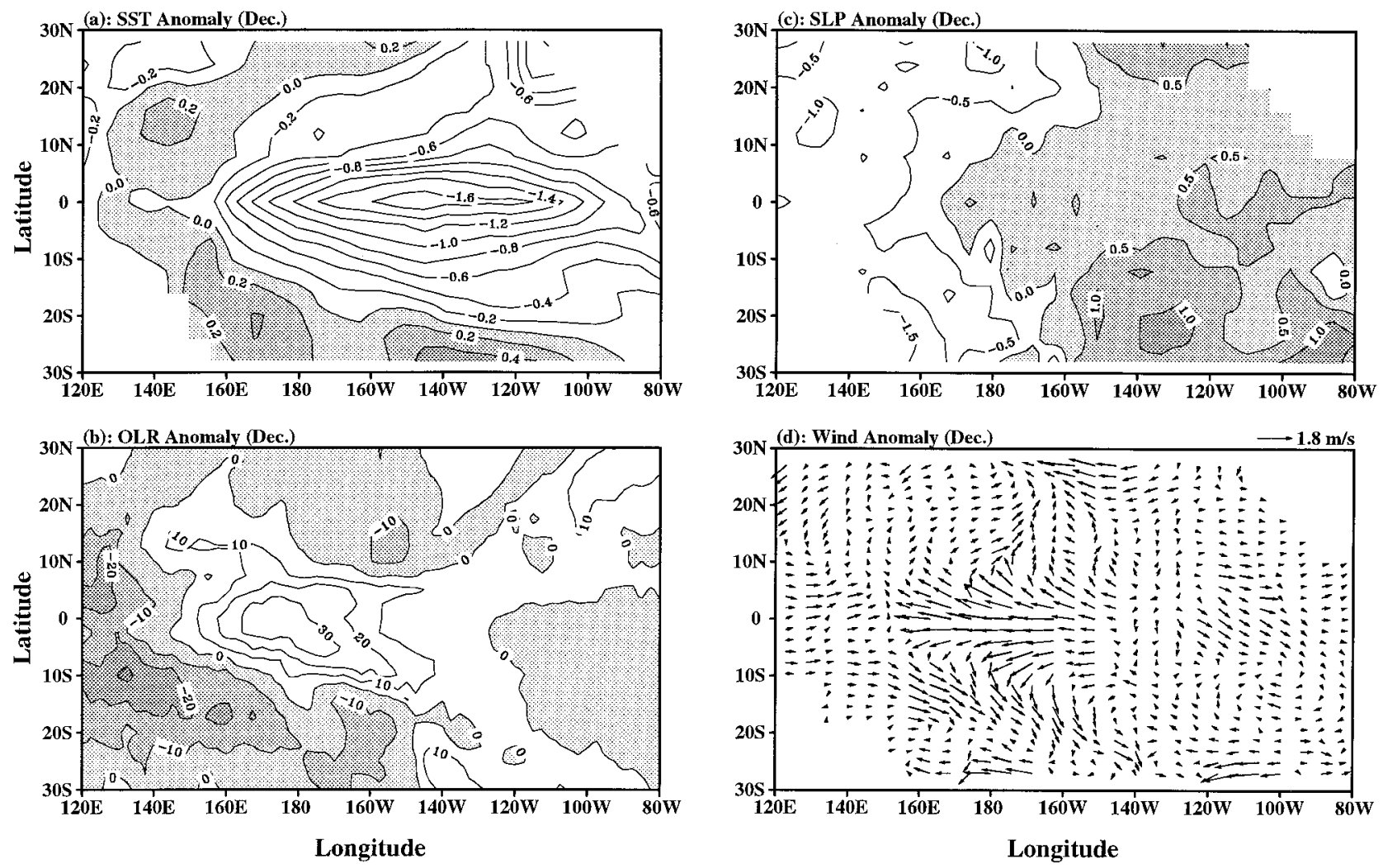

Figure 2. The horizontal structures of the tropical Pacific (a) SST anomalies $\left({ }^{\circ} \mathrm{C}\right)$, (b) OLR anomalies (W $\mathrm{m}^{-2}$ ), (c) SLP anomalies (mbar), and (d) surface wind anomalies $\left(\mathrm{m} \mathrm{s}^{-1}\right)$ in December for a composite La Niña. The La Niña composite is formed by taking the average December anomaly for 1955, 1964, 1970, 1975, 1984, and 1988.

Figure 21). The amplitude differences may be the result of two factors: (1) Figure 1 uses data from 1950 to 1992, whereas Rasmusson and Carpenter [1982] used data from 1949 to 1976; and (2) the Rasmusson and Carpenter [1982] data were filtered more both in time and space. As further evidenced by the regional time series shown next, the western Pacific interannual anomaly patterns are all robust features of ENSO.

Given our focus on western Pacific interannual variability, we define two new regional indices (Figure 3 ) in addition to the conventional ENSO indices. These additional indices show the covariability of the highly correlated regions for ENSO within the tropical Pacific. They are useful for tracking the evolution of ENSO and for diagnosing ENSO-related model performance. The conventional areal-average ENSO indices are as follows: Nino 1 over $90^{\circ}-80^{\circ} \mathrm{W}, 10^{\circ}-5^{\circ} \mathrm{S}$; Nino 2 over $90^{\circ}-80^{\circ} \mathrm{W}$, $5^{\circ} \mathrm{S}-0^{\circ}$; Nino3 over $150^{\circ}-90^{\circ} \mathrm{W}, 5^{\circ} \mathrm{S}-5^{\circ} \mathrm{N}$; and Nino4 over $160^{\circ} \mathrm{E}-150^{\circ} \mathrm{W}, 5^{\circ} \mathrm{S}-5^{\circ} \mathrm{N}$. Consistent with the observations in Plate 1 and Figures 2 and 3, the additional western Pacific indices are defined as follows: Nino5 over $120^{\circ}-140^{\circ} \mathrm{E}, 5^{\circ} \mathrm{S}-5^{\circ} \mathrm{N}$ and Nino6 over $140^{\circ}-160^{\circ} \mathrm{E}, 8^{\circ}-16^{\circ} \mathrm{N}$.

Comparisons of the SST anomalies between the Nino3 and Nino6 regions, the SLP anomalies between the Nino3 and Nino6 regions, and the zonal wind anomalies between the Nino4 and Nino5 regions are shown in Figures 4a, 4b, and 4c, respectively. Note the differences in scales between the different regional indices. For SST the Nino3 anomalies are about a factor of 3 larger than those in Nino6. For SLP the magnitudes of the Nino3 and Nino6 anomalies are the same. For the zonal winds the Nino4 anomalies are about a factor of 1.5 larger than those in Nino5. Both SST and SLP anomalies in the Nino3 region are out of phase with those in the Nino6 region. That is, the warm (cold) SST and low (high) SLP in the equatorial eastern Pacific during El Niño (La Niña) are accompanied by the cold (warm) SST and high (low) SLP in the off-equatorial western Pacific. Similarly, zonal wind anomalies in the central Pacific tend to be out of phase with those over the far western

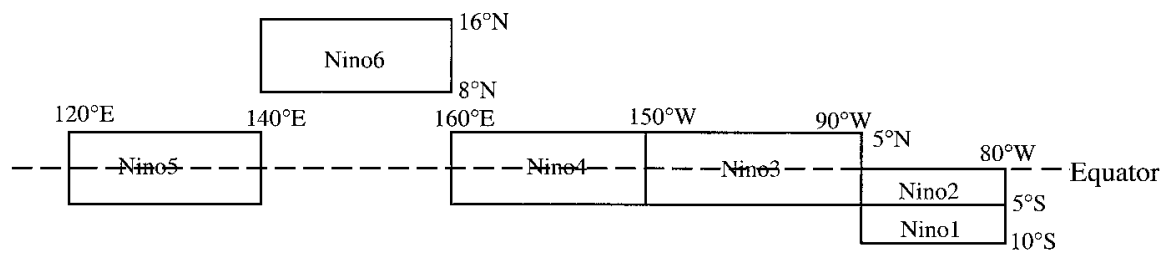

Figure 3. The Pacific ENSO index regions. 

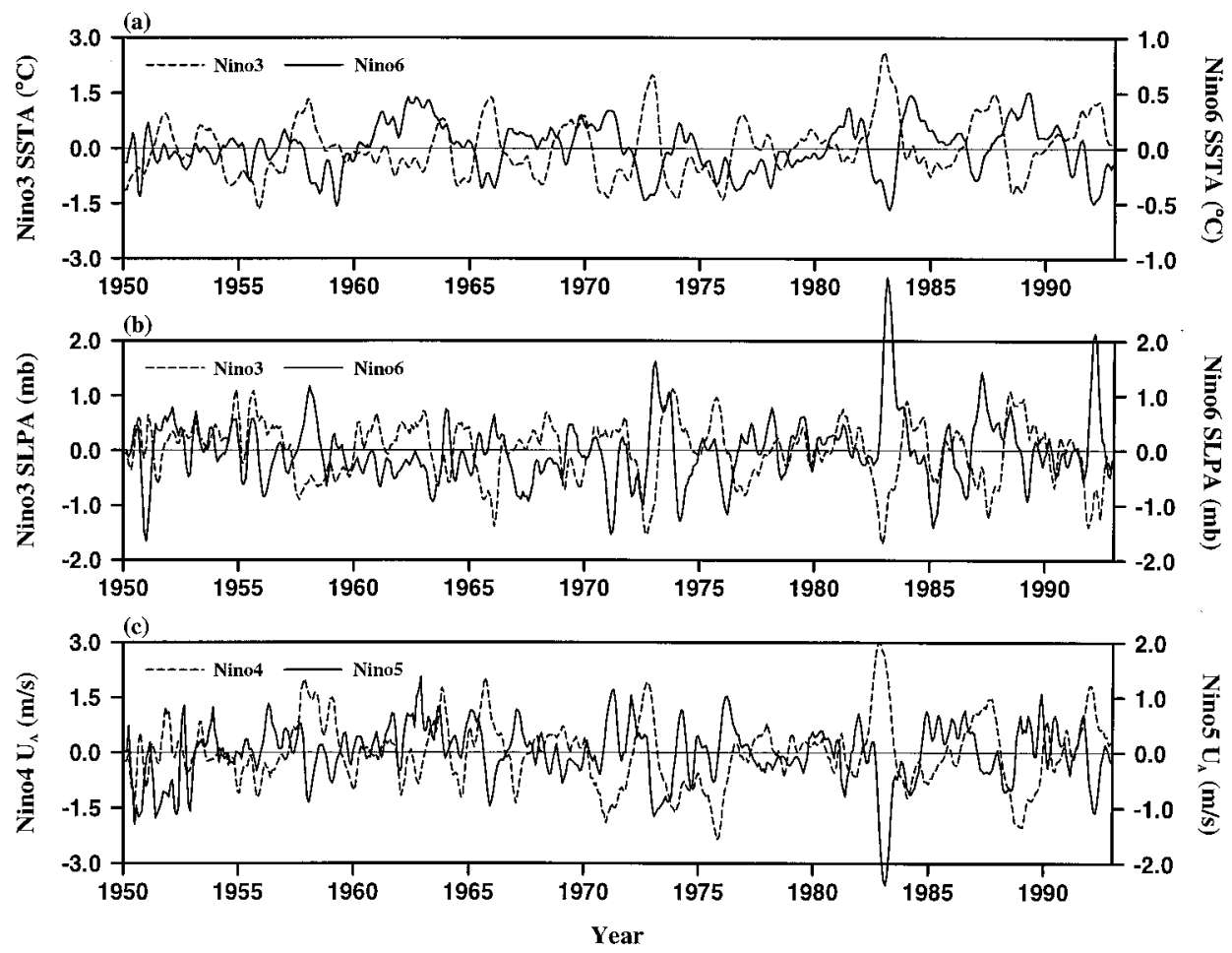

Figure 4. Three-month running means of the observed (a) Nino3 (dashed line) and Nino6 (solid line) SST anomalies, (b) Nino3 (dashed line) and Nino6 (solid line) SLP anomalies, and (c) Nino4 (dashed line) and Nino5 (solid line) zonal wind anomalies.

Pacific. During the peaks of the warm (cold) phase of ENSO, equatorial westerly (easterly) wind anomalies in the central Pacific are accompanied by equatorial easterly (westerly) wind anomalies over the far western Pacific.

\section{Atmospheric Response to Off-Equatorial SST Anomalies}

Observations in the previous section show that off-equatorial western Pacific cold (warm) SST and high (low) SLP anomalies are associated with equatorial easterly (westerly) winds over the far western Pacific during the warm (cold) phase of ENSO. In this section the Zebiak [1986] version of the Gill [1980] atmosphere is employed to show how the atmosphere responds to symmetric off-equatorial SST anomalies (exclusive of mean background states, Gill [1980] previously showed such response for an antisymmetric anomaly pattern). The atmospheric heating function $Q$ for this model contains two parts: $Q_{T}$ and $Q_{C}$. $Q_{T}$ corresponds to the local heating associated with the SST anomaly $T$, and $Q_{C}$ accounts for the low-level moisture convergence feedback. These two heating terms are expressed as

$$
\begin{aligned}
Q_{T} & =\alpha T \exp [(\bar{T}-29.8) / 16.7] \\
Q_{c} & =0 \quad(\bar{C}+C)>0, \bar{C}>0 \\
Q_{c} & =-\beta C \quad(\bar{C}+C) \leq 0, \bar{C} \leq 0 \\
Q_{C} & =-\beta(\bar{C}+C) \quad(\bar{C}+C) \leq 0, \bar{C}>0 \\
Q_{C} & =\beta \bar{C} \quad(\bar{C}+C)>0, \bar{C} \leq 0
\end{aligned}
$$

where the constant $\alpha=0.031 \mathrm{~m}^{2} \mathrm{~s}^{-3}{ }^{\circ} \mathrm{C}^{-1}$ and the efficiency factor for the convergence feedback process, $\beta=1.6 \times 10^{4} \mathrm{~m}^{2}$ $\mathrm{s}^{-2}$ [Zebiak, 1986]. The mean SST state $\bar{T}$ dependence in (1) gives relatively more atmospheric heating in the western $\mathrm{Pa}$ cific warm pool region than in the eastern Pacific cold tongue region for equal SST anomalies. $Q_{C}$ depends on both the mean wind convergence $\bar{C}$ and the anomalous wind convergence $C$. Usually, the strength of the mean convergence/divergence is large relative to the anomalous convergence/divergence so that either no feedback (2a) or anomalous convergence/divergence feedback (2b) applies. In regions where the mean convergence/ divergence is small however, the cases (2c) and (2d) apply.

The atmospheric response to off-equatorial western Pacific cold SST anomalies is shown in Figure 5. In all cases to be considered, $\bar{C}$ and $\bar{T}$ are taken from the December climatologies since we are interested in atmospheric responses to SST anomaly patterns during the peak phases of ENSO. A pair of symmetric, off-equatorial cold SST anomalies located at $10^{\circ} \mathrm{N}$, $150^{\circ} \mathrm{E}$ and $10^{\circ} \mathrm{S}, 150^{\circ} \mathrm{E}$ (Figure 5a) produces a pair of symmetric off-equatorial high SLP anomalies (Figure $5 b$ ). These offequatorial high SLP anomalies, in turn, produce equatorial easterly winds over the far western Pacific and equatorial westerly winds to the east of the cold SST anomalies (Figure 5c).

In addition to off-equatorial western Pacific cold SST anomalies, the warm phase of ENSO is characterized by warm SST anomalies in the equatorial east central Pacific. To view the atmospheric response to these combined SST anomalies during the warm phase of ENSO, we add a warm SST anomaly pattern in the equatorial east central Pacific as shown in Figure 6a. The atmospheric SLP response now consists of low SLP in the equatorial east central Pacific along with the off-equatorial high SLP patterns in the western Pacific (Figure 6b). Due to this SLP distribution, equatorial easterly winds exist over the far western Pacific along with enhanced equatorial westerly 

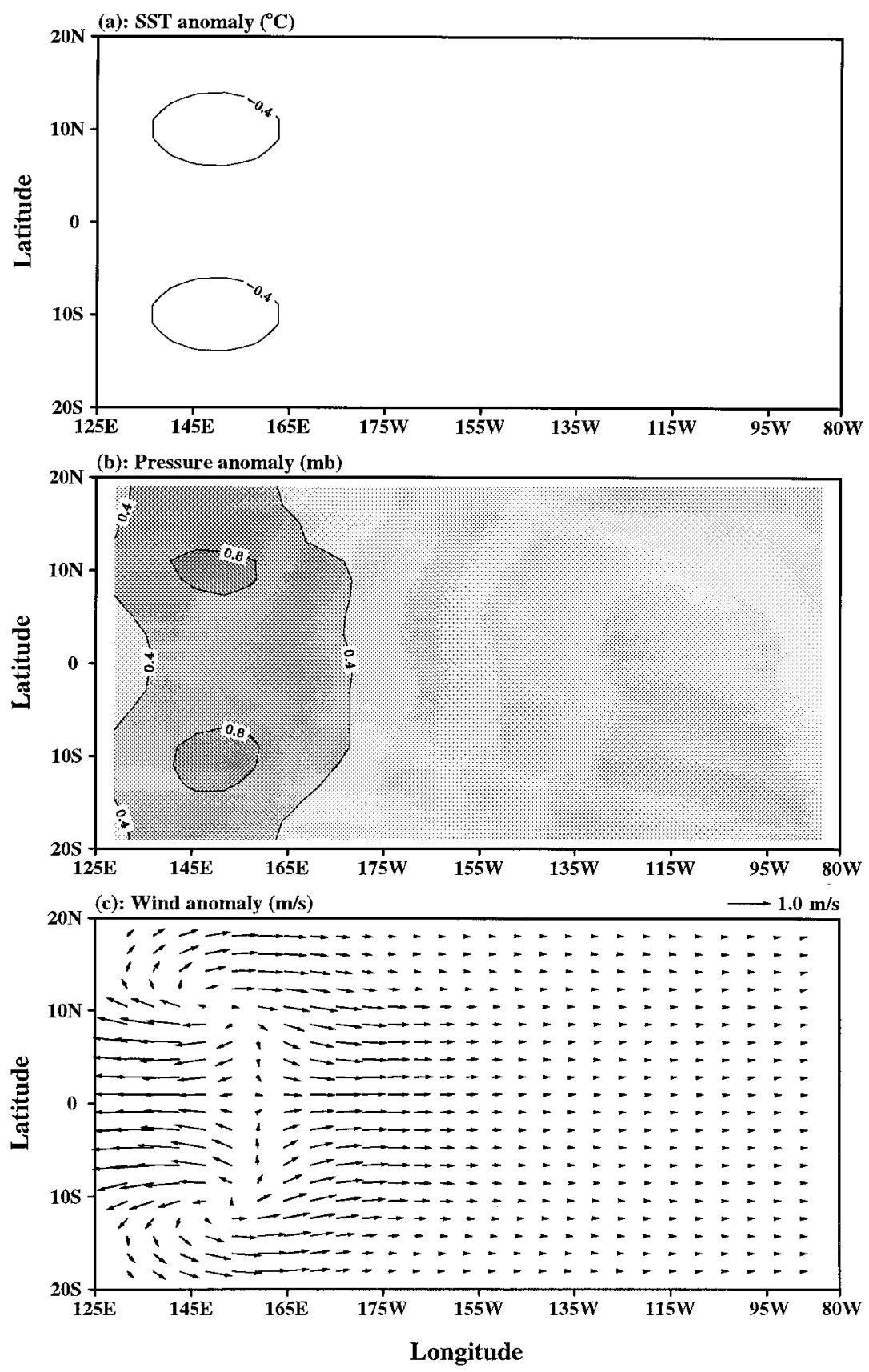

Figure 5. Atmospheric model response to off-equatorial western Pacific cold SST anomalies.

winds in the central Pacific (Figure 6c). From these experiments it is concluded that equatorial easterly winds over the far western Pacific, as observed during the warm phase of ENSO, can be produced by off-equatorial western Pacific SST anomalies. While it is recognized that equatorial westerly winds in the central Pacific during the warm phase of ENSO are primarily produced by equatorial east central Pacific warm SST anomalies, a small portion of the equatorial westerly winds in the central Pacific during the warm phase of ENSO may also be attributed to the off-equatorial western Pacific SST anomalies (see Figure 5c).

To see how the atmosphere responds to an SST anomaly pattern similar to the cold phase of ENSO and to examine whether or not the model produces symmetric responses to warm and cold SST anomalies, we reverse the signs of the forced SST anomaly patterns of Figures 5 and 6, producing the atmospheric responses shown in Figures 7 and 8, respectively. The off-equatorial western Pacific warm SST anomaly pattern produces a symmetric off-equatorial low SLP anomaly pattern (Figure 7b). This off-equatorial western Pacific low SLP anomaly pattern, in turn, produces equatorial westerly winds over the far western Pacific and equatorial easterly winds to the east of the warm SST anomalies (Figure 7c). Figure 8 shows that an SST anomaly pattern similar to the cold phase of ENSO produces high SLP in the equatorial east central Pacific and a symmetric pattern of off-equatorial low SLP in the western Pacific (Figure $8 b$ ). This SLP anomaly pattern, in turn, produces equatorial westerly winds over the far western Pacific 

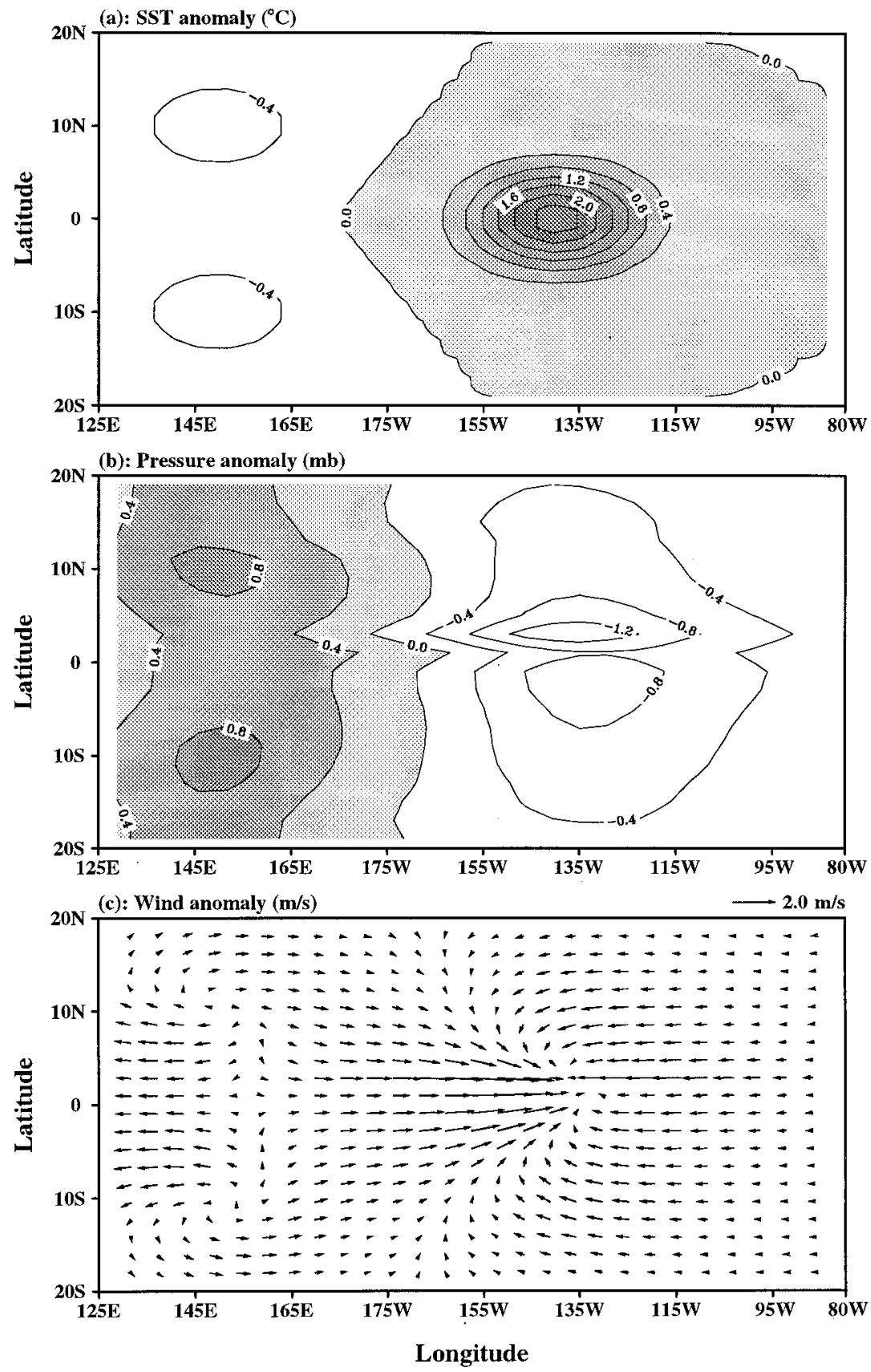

Figure 6. Atmospheric model response to both off-equatorial western Pacific cold SST anomalies and equatorial eastern Pacific warm SST anomalies.

and the equatorial easterly winds in the central Pacific (Figure $8 \mathrm{c})$. Both Figures 6 and 8 show that the initiation of equatorial easterly or westerly winds over the far western Pacific requires off-equatorial SST anomalies in the western Pacific of only modest amplitude. Thus while the amplitude of observed offequatorial western Pacific SST anomalies is small compared to equatorial eastern Pacific SST anomalies, they are sufficient to produce equatorial easterly or westerly winds over the far western Pacific.

Comparing Figures 6 and 8 (or Figures 5 and 7) shows that the atmospheric responses in the western Pacific are equally sensitive to cold and warm off-equatorial SST anomalies. This is in contrast to the eastern Pacific, where the atmospheric responses are more sensitive to warm SST anomalies than cold
SST anomalies (again compare Figures 6 and 8). This response inhomogeneity is a consequence of the atmospheric heating parameterization that depends on both the mean and anomalous wind divergence fields. In the western Pacific region of symmetric off-equatorial SST anomalies, the mean wind field in December is convergent (not shown), and the magnitude of this mean convergence is large compared with the anomalous convergence/divergence. So, the anomalous convergence feedback case (2b) applies, and the model atmospheric heatings for both the off-equatorial cold and warm SST anomalies are $Q_{T}$ $-\beta C$. Since the off-equatorial cold and warm SST anomalies result in anomalous divergence $(C>0)$ and convergence $(C<0)$, respectively, their atmospheric responses are equally sensitive. In the eastern Pacific, there is a meridional asymme- 

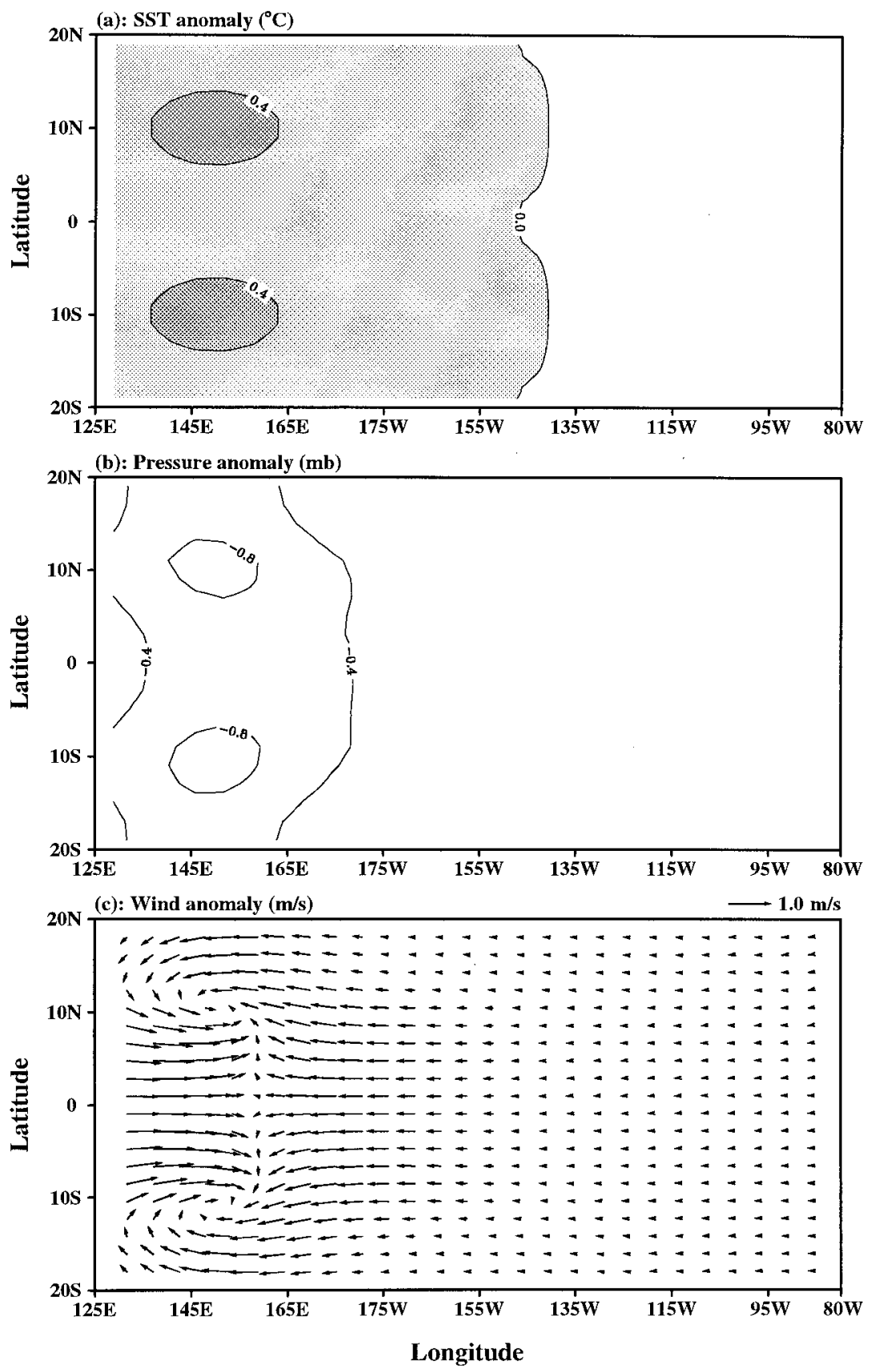

Figure 7. Atmospheric model response to off-equatorial western Pacific warm SST anomalies.

try of mean states. The mean wind convergence is located to the north of the equator, associated with the Intertropical Convergence Zone (ITCZ), whereas the mean wind fields are divergent to the south of the ITCZ. In the region south of the equator, where the strength of the mean divergence is large compared with anomalous convergence/divergence, the case of no feedback (2a) applies. The atmospheric heatings for both cold and warm SST anomalies are $Q_{T}$; thus the atmospheric responses are also equally sensitive. In the transitional region (between the mean wind convergence and divergence) just north of the equator, the mean wind convergence is small (nearly zero), and the feedbacks of cases (2d) and (2c) apply. The atmospheric heatings for cold and warm SST anomalies correspond to $Q_{T}-\beta \bar{C}$ and $Q_{T}-\beta(\bar{C}+C)$, respectively; the atmospheric responses are thus more sensitive to warm
SST anomalies than cold SST anomalies as shown in Figures 6 and 8 . This behavior may be one of the reasons why the ZC model favors simulating the warm phase of ENSO.

By virtue of convergence feedback in the off-equatorial western Pacific region, resulting in model atmospheric heating of the form $Q_{T}-\beta C$, versus no convergence feedback in the equatorial eastern Pacific, resulting in model atmospheric heating of the form $Q_{T}$, the model atmospheric response in the Nino6 region for a given SST anomaly is larger than that in the Nino3 region. This provides an explanation for the observations that the SLP anomaly scale in the Nino6 and Nino3 regions are the same despite the SST anomaly scale being larger in Nino3 than in Nino6 (Figure 4). Even though the SST anomalies are smaller in the off-equatorial western Pacific than in the equatorial eastern Pacific, they are sufficient to 

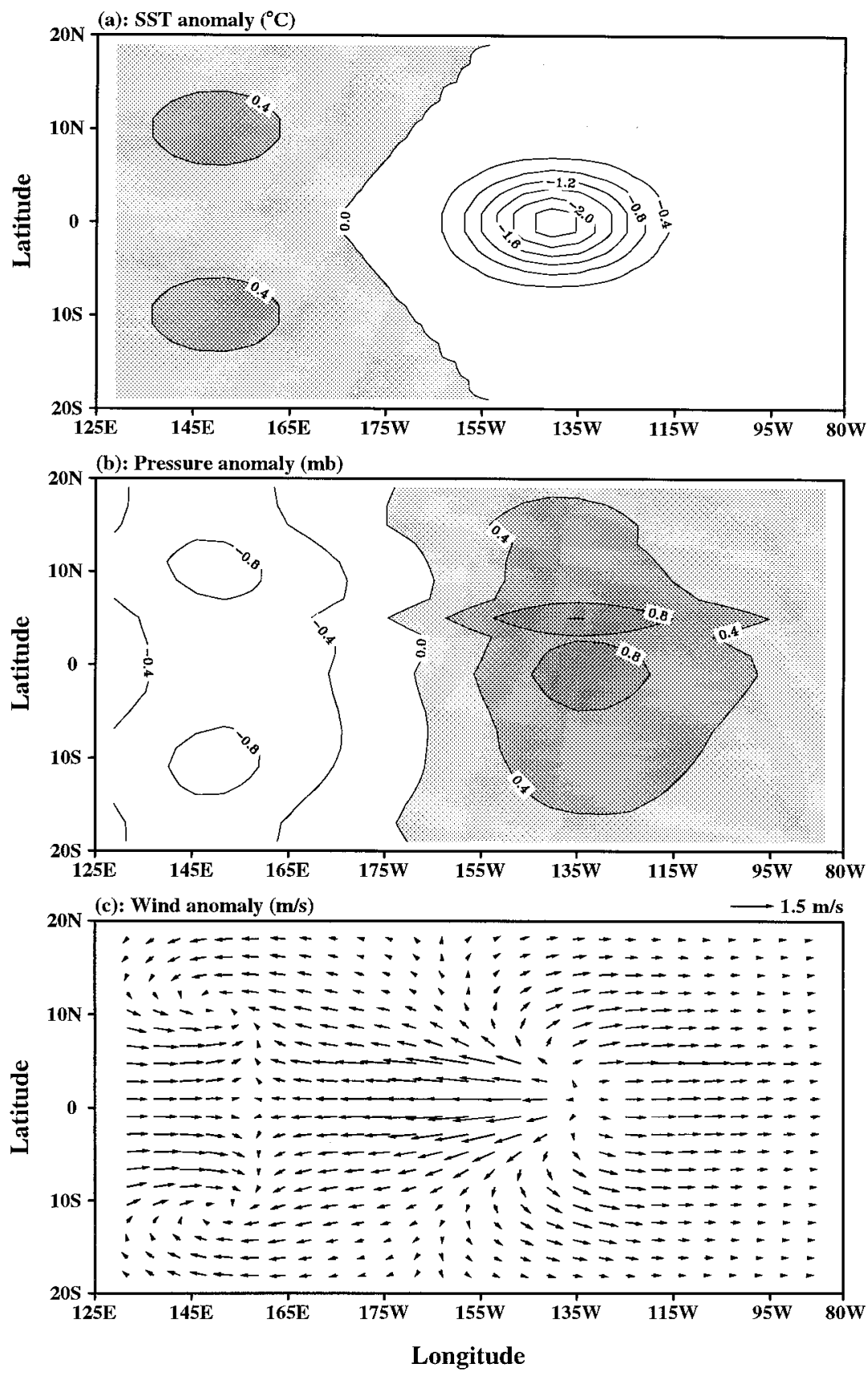

Figure 8. Atmospheric model response to both off-equatorial western Pacific warm SST anomalies and equatorial eastern Pacific cold SST anomalies.

produce atmospheric responses of comparable amplitude to those in the equatorial eastern Pacific. This is because the atmospheric mean state is convergent in the western Pacific and divergent in the equatorial eastern Pacific. Thus the lowlevel moisture feedback process, which depends on the atmospheric mean background state, favors anomaly growth in the western Pacific.

\section{Coupled Ocean-Atmosphere Model}

The atmospheric model showed that off-equatorial western Pacific cold (warm) SST anomalies can produce equatorial easterly (westerly) winds over the far western Pacific. Can this mechanism operate in a coupled ocean-atmosphere system? The coupled ZC model is employed to address this question. The ocean part of the model is a reduced gravity model consisting of an active upper layer with a fixed depth surface mixed layer, overlying a motionless deep layer. The atmosphere part is the Zebiak [1986] model used in section 3. The model calculates anomalies occurring about seasonally varying mean states, as discussed in ZC. Here, we modify the ZC model to include an idealized rendition of the behavior observed in the western Pacific.

The basic premise, as developed by Weisberg and Wang [1997a, b], is that off-equatorial wind stress curl due to equatorial westerly or easterly wind stress anomalies can alter off- 
equatorial SST and hence the equatorial wind stress. The offequatorial wind stress curl affects both the off-equatorial thermocline displacement and the vertical velocity. The effects of vertical advection on the SST anomaly in the ZC model include two terms: $[M(\bar{w}+w)-M(\bar{w})] \partial \bar{T} / \partial z$ and $M(\bar{w}+$ $w) \partial T / \partial z$, where $M(x)$ is a function equal to $x$ if $x$ is positive and zero if $x$ is negative; $T(\bar{T})$ is the anomalous (mean) SST; and $w(\bar{w})$ is the anomalous (mean) vertical velocity. Both terms are related to $w$ at the base of the surface mixed layer $\left(H_{s}=50 \mathrm{~m}\right)$. This $w$ contains the divergences of both the upper layer horizontal velocity $(\mathbf{u})$ and the surface mixed layer horizontal velocity $\left(\mathbf{u}_{s}\right)$

$$
w=H_{s} \nabla \cdot \mathbf{u}+H_{s}\left(1-H_{s} / H\right) \nabla \cdot \mathbf{u}_{s}
$$

such that $w$ can be further divided into its constituent terms

$$
w=w_{h}+w_{\text {curl }}+w_{\text {div }}+w_{\text {taux }}+w_{\text {tauy }}
$$

where

$$
\begin{aligned}
w_{h} & =-\frac{H_{s}}{H}\left(\frac{\partial h}{\partial t}+\gamma h\right) \\
w_{\text {curl }} & =\frac{\left(H-H_{s}\right) \beta_{0} y}{\rho H\left(\gamma_{s}^{2}+\beta_{0}^{2} y^{2}\right)}\left(\frac{\partial \tau^{y}}{\partial x}-\frac{\partial \tau^{x}}{\partial y}\right) \\
w_{\text {div }} & =\frac{\left(H-H_{s}\right) \gamma_{s}}{\rho H\left(\gamma_{s}^{2}+\beta_{0}^{2} y^{2}\right)}\left(\frac{\partial \tau^{x}}{\partial x}+\frac{\partial \tau^{y}}{\partial y}\right) \\
w_{\text {taux }} & =\frac{\beta_{0}\left(H-H_{s}\right)\left(\beta_{0}^{2} y^{2}-\gamma_{s}^{2}\right)}{\rho H\left(\gamma_{s}^{2}+\beta_{0}^{2} y^{2}\right)^{2}} \tau^{x} \\
w_{\text {tauy }} & =-\frac{2\left(H-H_{s}\right) \gamma_{s} \beta_{0}^{2} y}{\rho H\left(\gamma_{s}^{2}+\beta_{0}^{2} y^{2}\right)^{2}} \tau^{y}
\end{aligned}
$$

$h$ is the anomalous thermocline, $\tau^{x}\left(\tau^{y}\right)$ is the zonal (meridional) wind stress, $\rho$ is the seawater density, the upper layer thickness $H=150 \mathrm{~m}$, the damping coefficient $\gamma=(2.5$ year $)^{-1}$, the mixed layer damping coefficient $\gamma_{s}=(2 \text { days })^{-1}$, and the planetary vorticity gradient $\beta_{0}=2.29 \times 10^{-11} \mathrm{~m}^{-1}$ $\mathrm{s}^{-1}$. The $w$ is therefore determined by thermocline displacement, wind stress curl, wind stress divergence, zonal wind stress, and meridional wind stress. In off-equatorial regions, $w$ is primarily controlled by the wind stress curl and the thermocline displacement, whereas on the equator it is primarily controlled by the zonal wind stress and the thermocline displacement. During the warm (cold) phase of ENSO, cold (warm) SST anomalies are observed in the off-equatorial western $\mathrm{Pa}$ cific, suggesting that wind stress curl and thermocline displacement may be responsible there.

In the off-equatorial western Pacific the wind stress curl affects the thermocline displacement both locally and by the integrated effect of forced off-equatorial Rossby waves [e.g., Kessler, 1990]. Anomalous thermocline displacement in the ZC model affects SST through the term $M(\bar{w}+w) \partial T / \partial z$. The anomalous vertical temperature gradient is calculated as a difference between the SST anomaly $T$ and the subsurface temperature anomaly $T_{\text {sub }}$ :

$$
\frac{\partial T}{\partial z}=\frac{T-T_{\text {sub }}}{H_{1}} .
$$

The ZC model uses $H_{1}=100 \mathrm{~m}$ (i.e., $T_{\text {sub }}$ is evaluated at $100 \mathrm{~m}$ since the vertical velocity anomalies are calculated at
$50 \mathrm{~m}$ ), and $T_{\text {sub }}$ is parameterized in terms of the thermocline displacement anomaly $h$ :

$$
T_{\text {sub }}=A_{1}\left\{\tanh \left[B_{1}(\bar{h}(x)+h)\right]-\tanh \left[B_{1} \bar{h}(x)\right]\right\} \quad h \geq 0
$$

$$
T_{\text {sub }}=A_{2}\left\{\tanh \left[B_{2}(\bar{h}(x)-h)\right]-\tanh \left[B_{2} \bar{h}(x)\right]\right\} \quad h<0
$$

where $A_{1}=28^{\circ} \mathrm{C}, B_{1}=1.25 \times 10^{-2} \mathrm{~m}^{-1}, A_{2}=-40^{\circ} \mathrm{C}$, and $B_{2}=3.0 \times 10^{-2} \mathrm{~m}^{-1}$. The mean thermocline depth, $\bar{h}(x) \equiv \bar{h}_{E}(x)$, is specified using an observed equatorial thermocline distribution after Colin et al. [1971]. Figure 9a shows the structure of the mean thermocline depth, $\bar{h}_{E}(x)$, for the standard ZC model. The mean thermocline is independent of latitude and is shallow in the eastern Pacific, whereas it is deep and zonally uniform in the western Pacific. Accordingly, $T_{\text {sub }}$ is much more sensitive to thermocline displacements in the eastern Pacific than in the western Pacific.

By not including a meridional structure in the mean thermocline depth, the standard ZC model suppresses offequatorial SST variations associated with wind stress curl, especially in the western Pacific where the mean thermocline depth is deep. Consistent with our observationally based premise, we modify the $\mathrm{ZC}$ model by adding an idealized meridional structure to the mean thermocline depth of the form

$$
\bar{h}(x, y)=\bar{h}_{E}(x)-h_{0}(x) \sin ^{2}\left(\frac{2 \pi}{40^{\circ}} y\right)
$$

where $\bar{h}_{E}(x)$ is the standard mean thermocline depth of the ZC model and $h_{0}(x)$ is the meridional structure amplitude for the mean thermocline. The value of $h_{0}(x)$ is $0 \mathrm{~m}$ to the east of $160^{\circ} \mathrm{W}$ and $65 \mathrm{~m}$ to the west of the date line $\left(180^{\circ}\right)$, and $h_{0}(x)$ increases linearly between $160^{\circ} \mathrm{W}$ and $180^{\circ}$. The resulting mean thermocline depth is shown in Figure $9 b$. In contrast with the standard ZC model (Figure 9a), the western Pacific now has a relatively shallow mean thermocline at $10^{\circ} \mathrm{N}$ and $10^{\circ} \mathrm{S}$, whereas the remainder of the domain is the same as the standard case. As seen from (6), the sensitivity of $T_{\text {sub }}$ to thermocline displacement also depends upon the parameters $A_{1}, B_{1}, A_{2}$, and $B_{2}$. A western Pacific meridional structure of these parameters is also specified in a similar manner to that of the mean thermocline. Meridional structure amplitudes for $A_{1}, B_{1}, A_{2}$, and $B_{2}$ are specified as zero to the east of $160^{\circ} \mathrm{W}$ and $-2.0^{\circ} \mathrm{C}, 1.0 \times$ $10^{-2} \mathrm{~m}^{-1}, 8.0^{\circ} \mathrm{C}$, and $2.7 \times 10^{-2} \mathrm{~m}^{-1}$, respectively, to the west of the date line, and they increase linearly between $160^{\circ} \mathrm{W}$ and $180^{\circ}$. Such an idealized western Pacific meridional structure of (7) is used solely for the purpose of testing whether or not the mechanism of equatorial easterly wind initiation over the far western Pacific can operate in a coupled ocean-atmosphere system. Although (7) is not inconsistent with observations, more realistic simulations should employ more realistic thermocline climatology.

A regional comparison of the $T_{\text {sub }}$ parameterization on thermocline displacement between the standard ZC model and our modified model is shown in Figure 10. The solid lines denote the modified model, and the dashed lines denote the standard model (for which the $T_{\text {sub }}$ sensitivity to $h$ is independent of latitude). In the equatorial eastern Pacific (Figure 10a) the responses of $T_{\text {sub }}$ to $h$ for the standard and modified models are the same (solid and dashed lines overlap) since the parameters are unchanged in that region. $T_{\text {sub }}$ is more sensitive to positive $h$ than negative $h$, and this asymmetry may also ac- 
(a): Standard Hbar
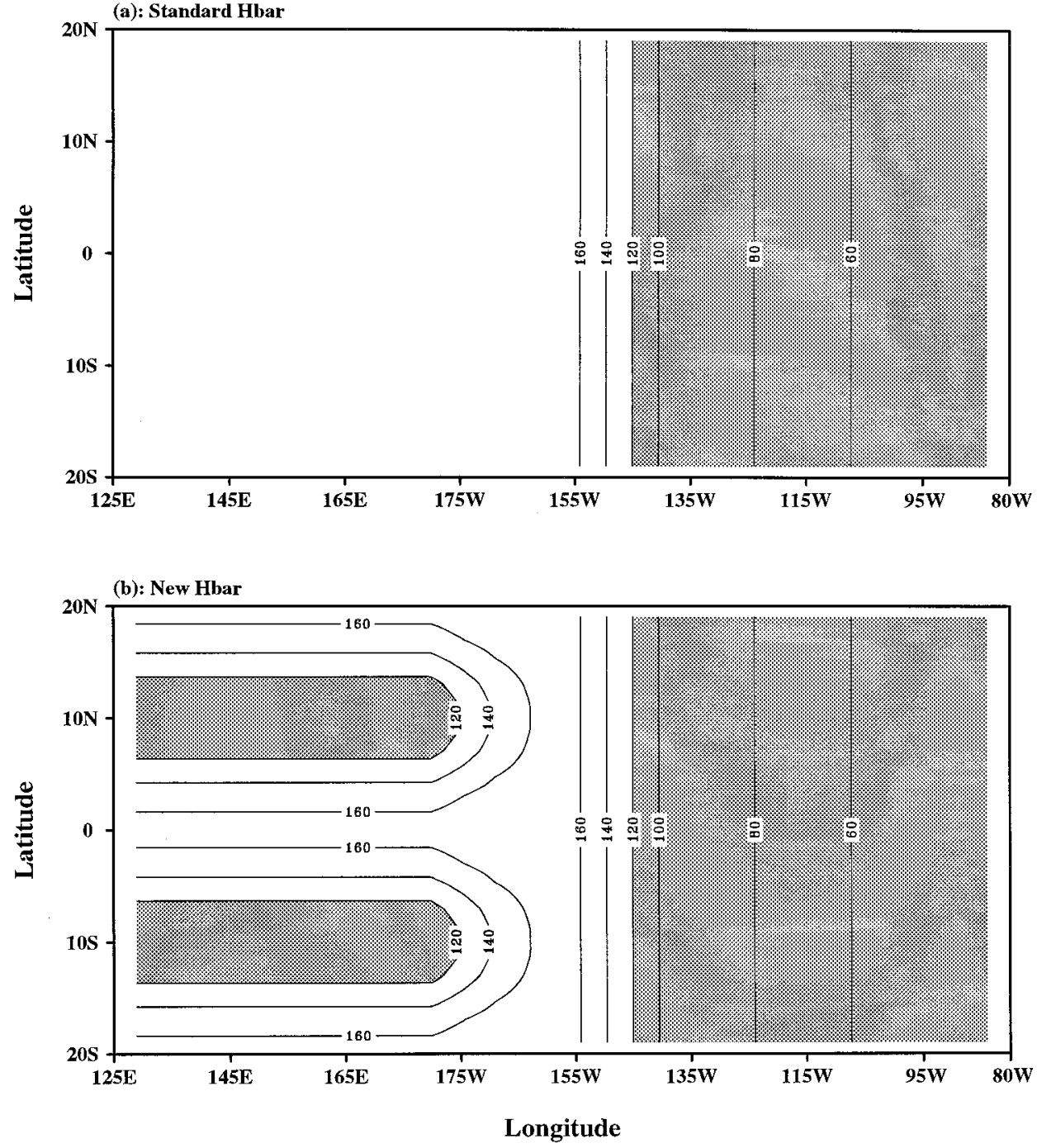

Figure 9. The mean thermocline depth specified in (a) the standard and (b) the modified coupled ZC models.

count for the asymmetric El Niño and La Niña oscillations in the $\mathrm{ZC}$ model shown in the next section. In the equatorial western Pacific (Figure 10b) the response of $T_{\text {sub }}$ to $h$ for the modified model is nearly the same as that for the standard model, and in both cases the $T_{\text {sub }}$ dependence on $h$ in the equatorial western Pacific is much smaller than that in the equatorial eastern Pacific (note the scale change for $T_{\text {sub }}$ among Figure 10 panels). For the off-equatorial western $\mathrm{Pa}$ cific region (Figure 10c) the modification greatly magnifies the off-equatorial $T_{\text {sub }}$ dependence on $h$ relative to that for the standard model. This added sensitivity of $T_{\text {sub }}$ with respect to $h$ in the off-equatorial region of the western Pacific can produce off-equatorial western Pacific cold SST anomalies and, subsequently, equatorial easterly wind anomalies over the far western Pacific, as shown in the next section.

\section{Results of the Coupled Ocean-Atmosphere Model}

Both the standard and new modified coupled oceanatmosphere models were run for 100 years. These runs were initiated by an imposed, Gaussian-distributed westerly wind anomaly centered on the equator between $145^{\circ} \mathrm{E}$ and $170^{\circ} \mathrm{W}$. This anomaly was held fixed for a period of 4 months and then removed, after which the model was run in a coupled sense without any external disturbances.

The resulting model Nino3 SST anomalies and Nino4 zonal wind anomalies for the standard and modified models are shown in Figures 11 and 12, respectively. For these equatorial eastern and central Pacific regions, the results for the standard and modified models are qualitatively similar. Both show aperiodic interannual oscillations of similar amplitude, with the model ENSO being phase locked to the seasonal cycle such that peak warming occurs around the end of the calendar year. The coupled models simulate the warm phase of ENSO better than the cold phase in that both Figures 11 and 12 show asymmetric oscillations having relatively small negative SST and zonal wind anomalies. This asymmetric behavior may result from two factors. The first is the asymmetric dependence of $T_{\text {sub }}$ on $h$. As shown in Figure 10a, the model is more sensitive to positive than negative $h$ in the eastern Pacific. Second, the Zebiak [1986] modification to the Gill [1980] atmosphere is more sensitive to warm SST anomalies than to 

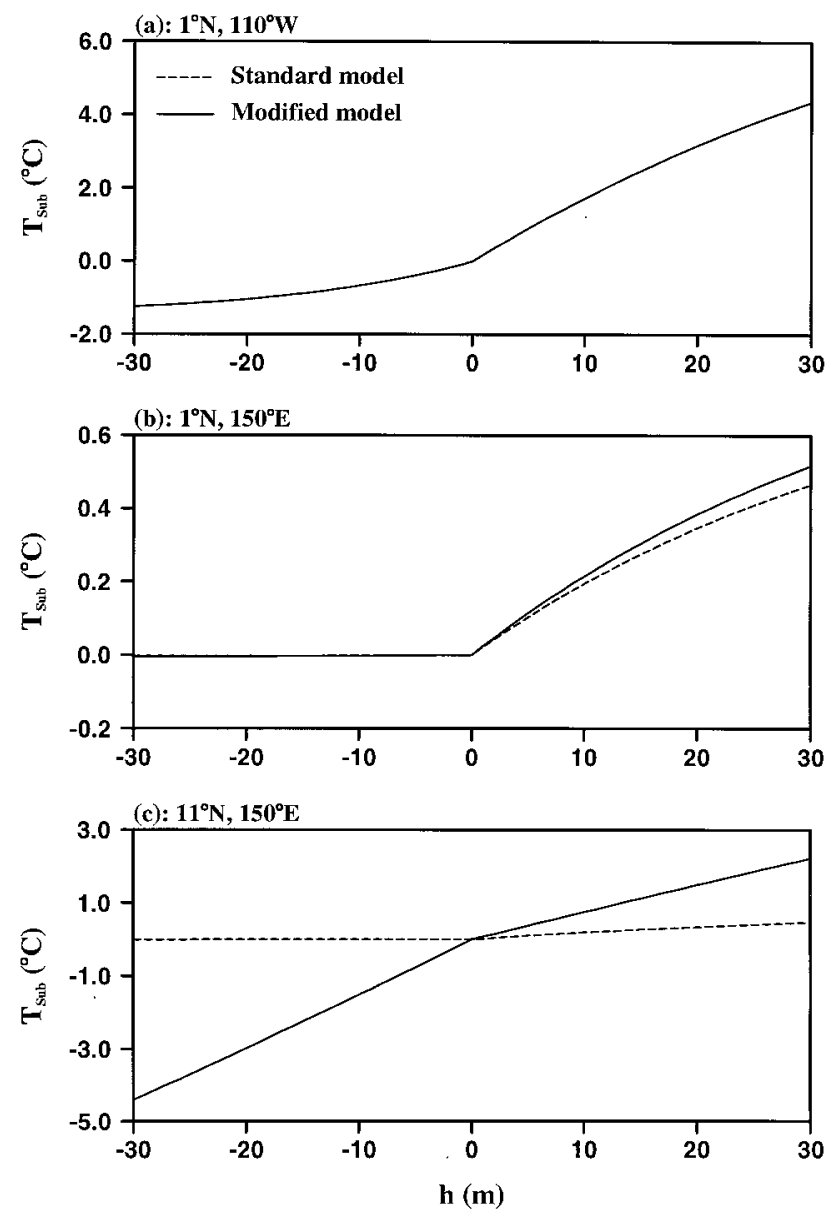

Figure 10. Regional comparison of the $T_{\text {sub }}$ parameterization on $h$ between the standard and modified ZC models. The solid lines denote the modified model, and the dashed lines denote the standard model. cold SST anomalies in the equatorial eastern Pacific, as discussed in section 3 . These two factors tend to accentuate the warm phase of ENSO in the coupled model.

Comparisons between the evolution of the SST and surface wind anomalies during a warm event between the standard and modified models are given in Figures 13, 14, 15, and 16. Shown are the horizontal structures of the SST and wind anomalies for the months of August, December, March, and June, respectively, for model integration years 44 (standard model) and 37 (modified model). Both models show warm SST anomalies in the equatorial eastern Pacific with westerly wind anomalies to the west of these warm SST anomalies by August. However, for the modified model these anomalies extend farther west than for the standard model. In particular, for the modified model the region of maximum equatorial westerly wind anomalies is located in the central Pacific, more consistent with observations. Neither case shows off-equatorial western Pacific SST anomalies at this time, and the associated equatorial easterly wind anomalies over the far western Pacific are nearly zero.

The model peak El Niño occurs in December for either the standard or the modified model (Figure 14). Both the SST and the westerly wind anomaly patterns for the modified model are shifted westward relative to those for the standard model, in better agreement with observations. The modified model results now show off-equatorial western Pacific cold SST anomalies and equatorial easterly winds over the far western Pacific. Consistent with the diagnosis in the previous section (Figure 5), this off-equatorial western Pacific SST anomaly pattern induces a similar high SLP anomaly pattern that, in turn, produces equatorial easterly winds over the far western Pacific. Thus the mechanism of off-equatorial western Pacific cold SST anomalies initiating equatorial easterly winds over the far western Pacific is operant within the modified coupled model.

By March (Figure 15), the equatorial eastern Pacific warm
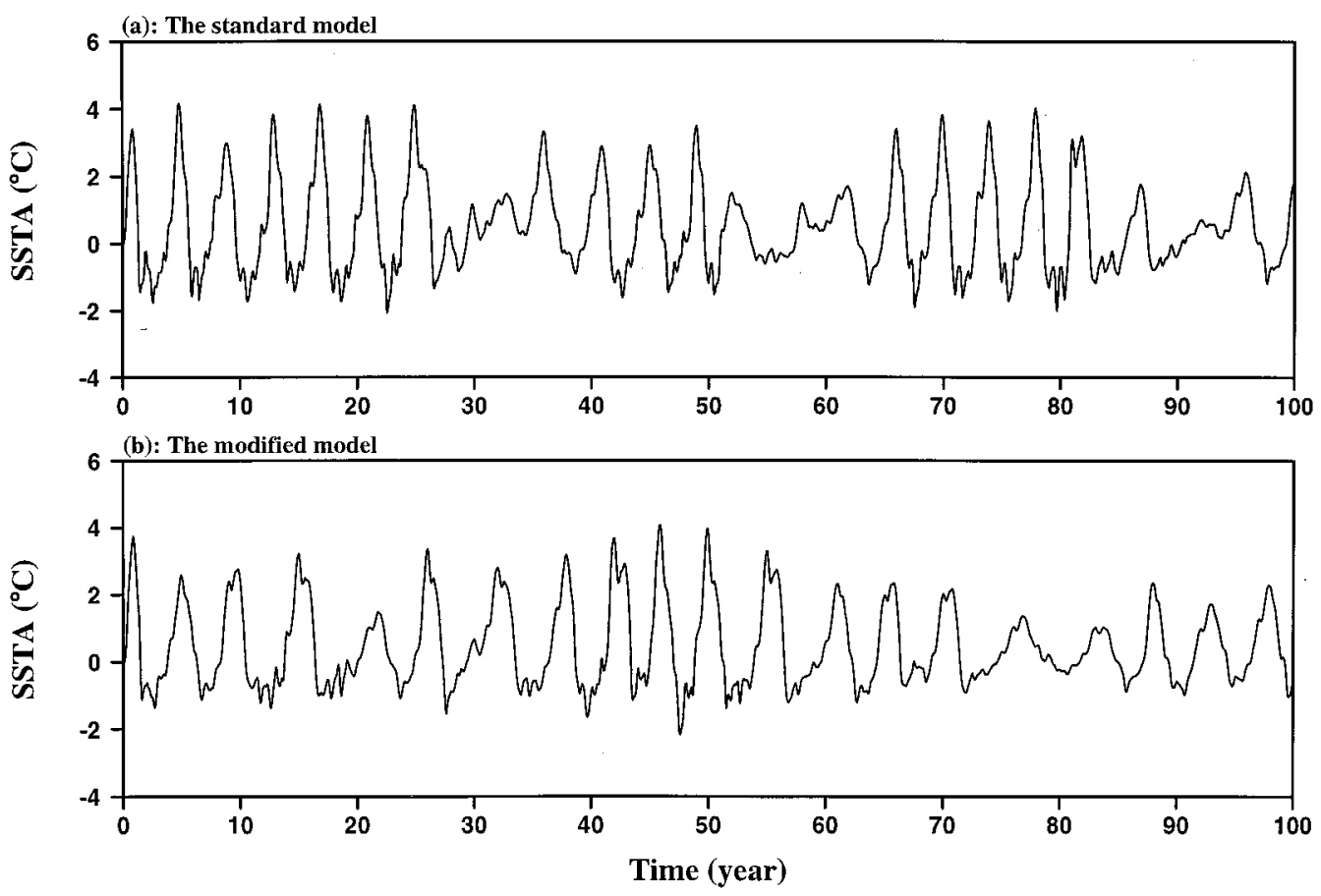

Figure 11. The Nino3 SST anomalies from (a) the standard and (b) the modified models. 

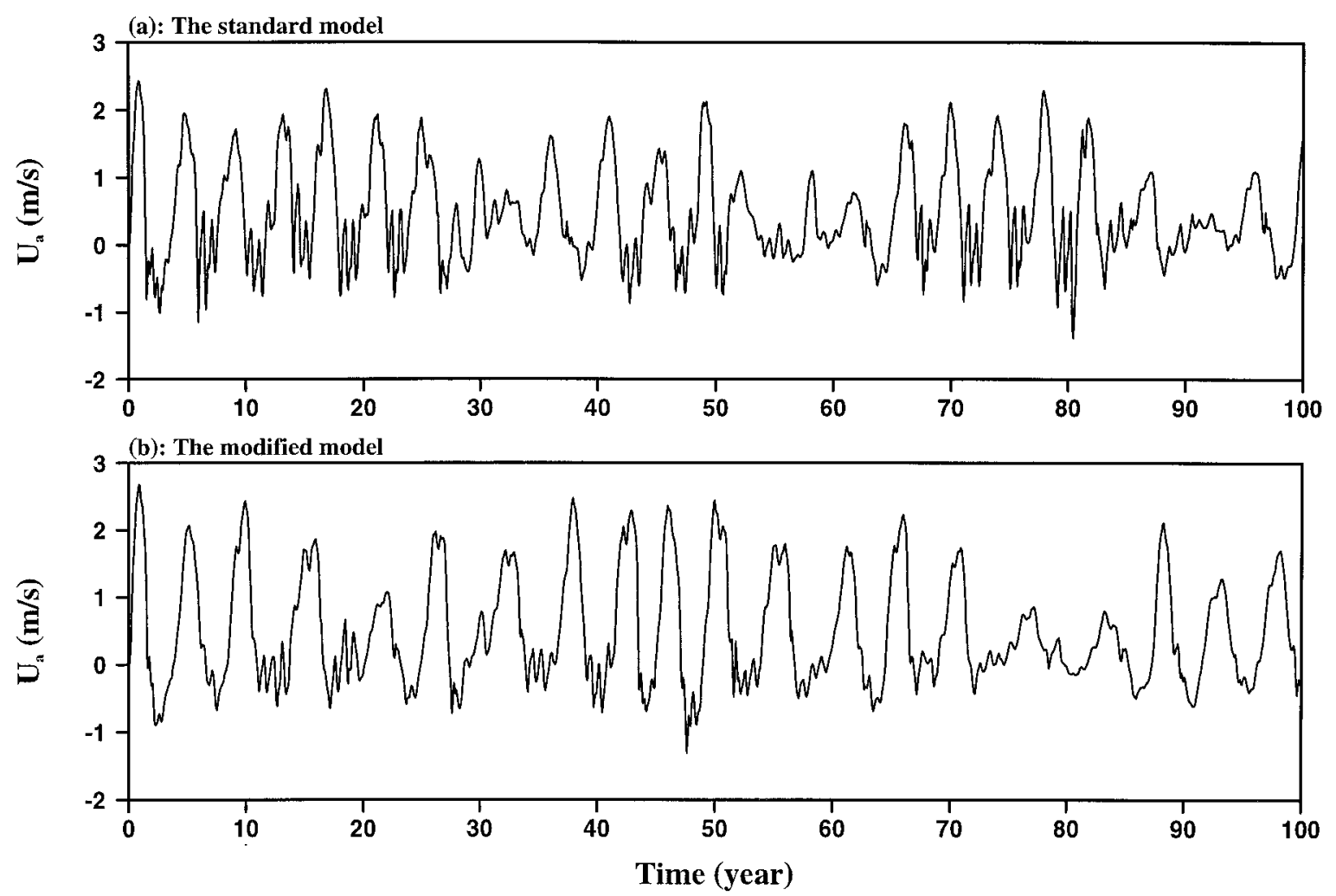

Figure 12. The Nino4 zonal wind anomalies from (a) the standard and (b) the modified models.

The Standard Model
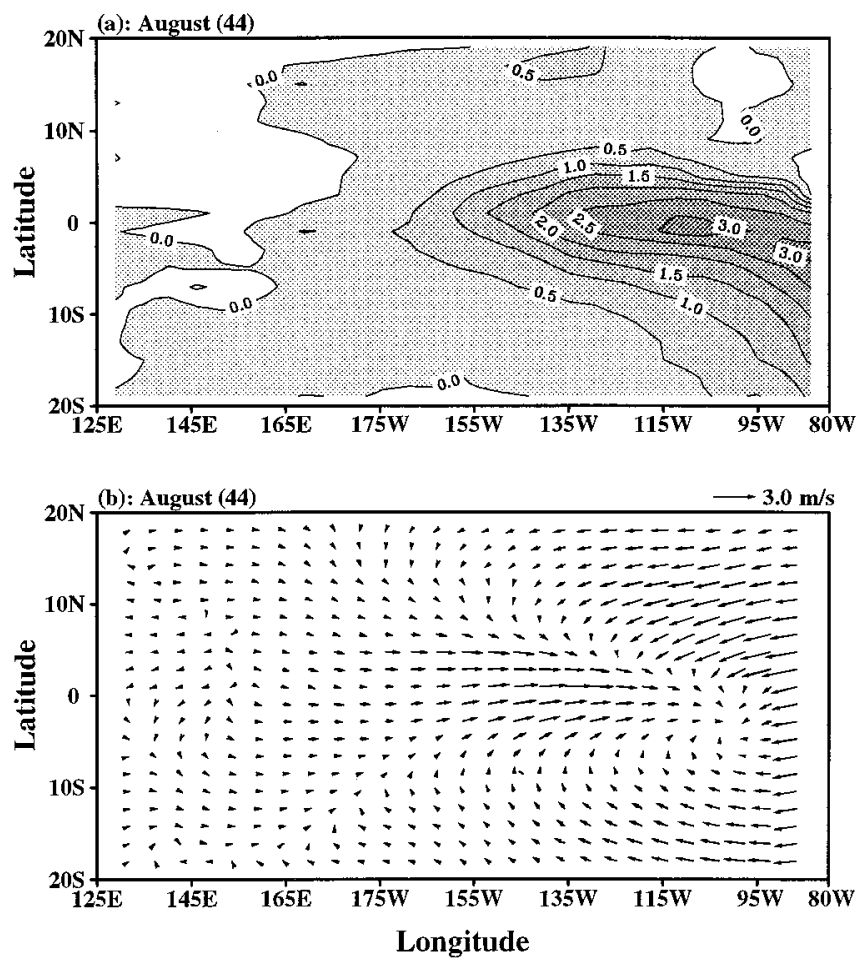

The Modified Model
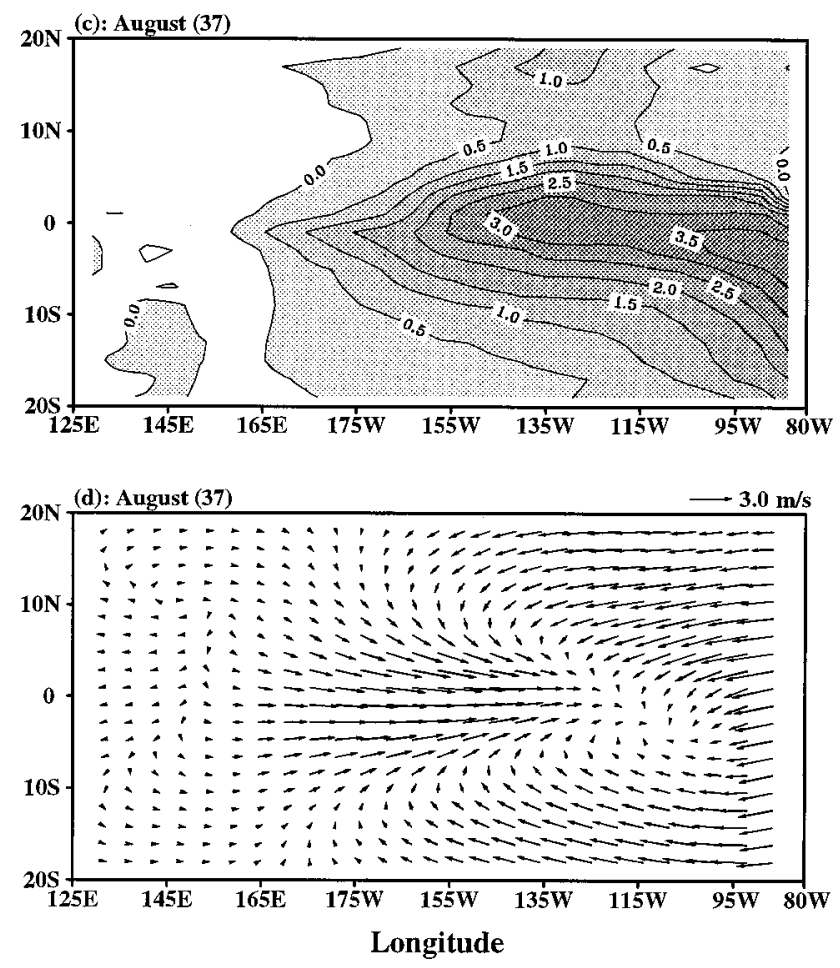

Figure 13. Comparisons of the horizontal structures for the (a and c) SST and (b and d) surface wind anomalies between the (left) standard and (right) modified models for a warm El Niño event during August. 


\section{The Standard Model}
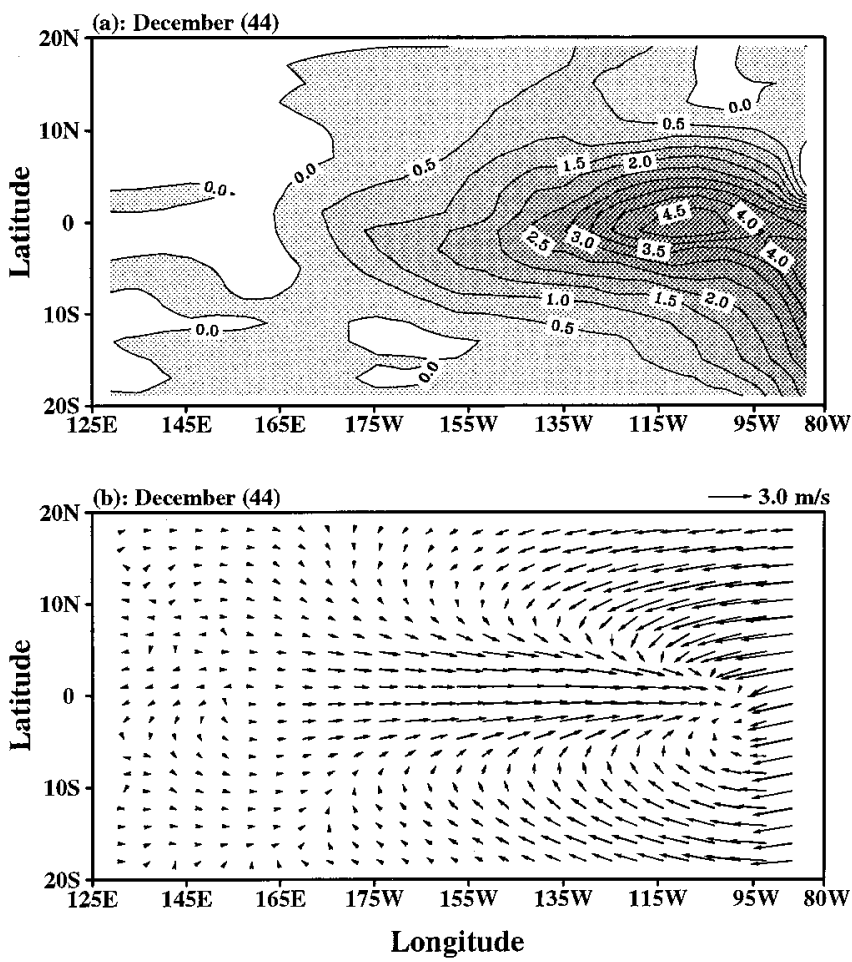

The Modified Model
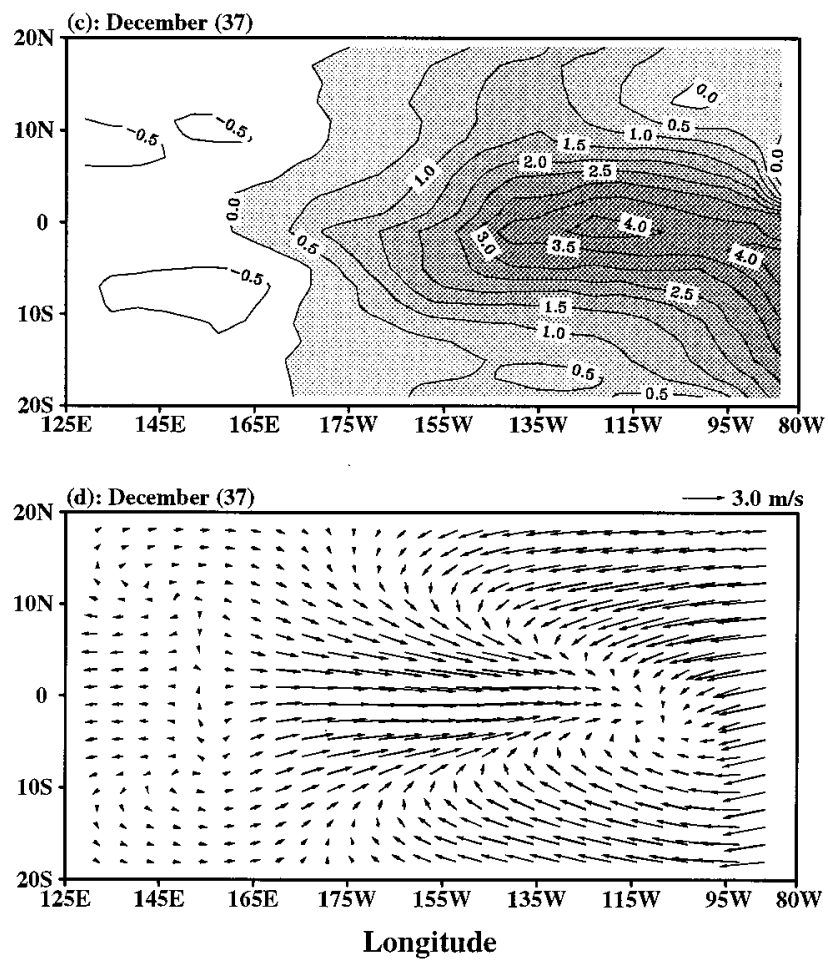

Figure 14. Comparison of the horizontal structures for the (a and c) SST and (b and d) surface wind anomalies between the (left) standard and (right) modified models for a warm El Niño event during December.

The Standard Model
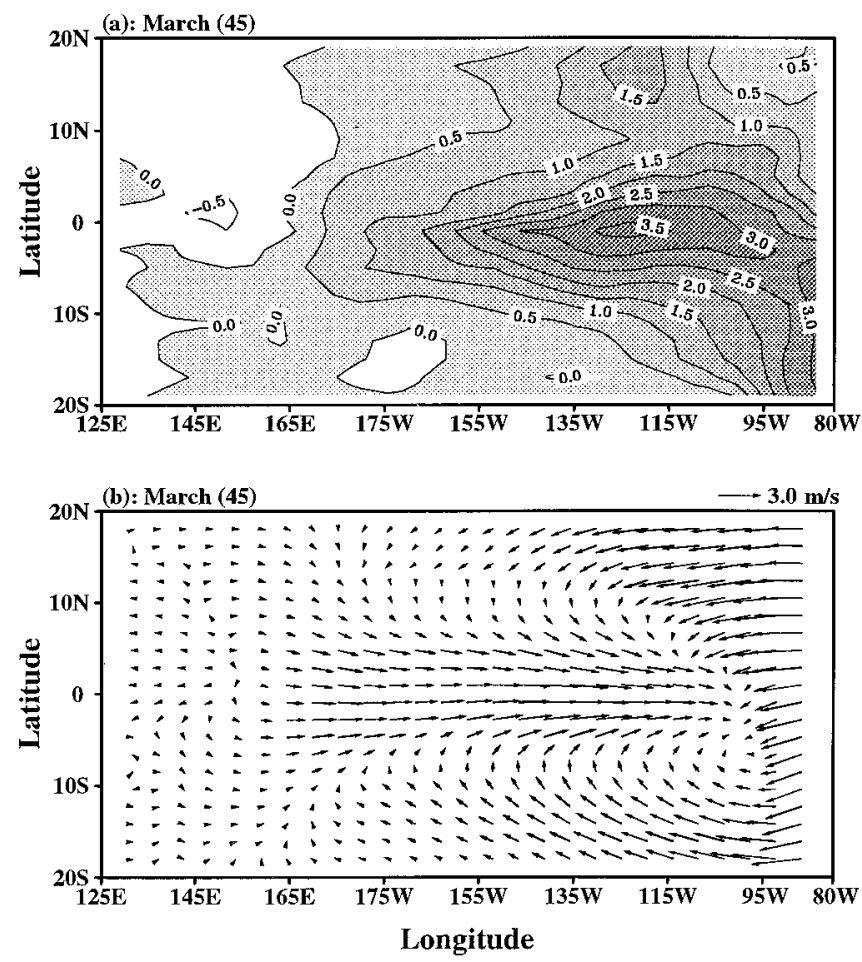

The Modified Model
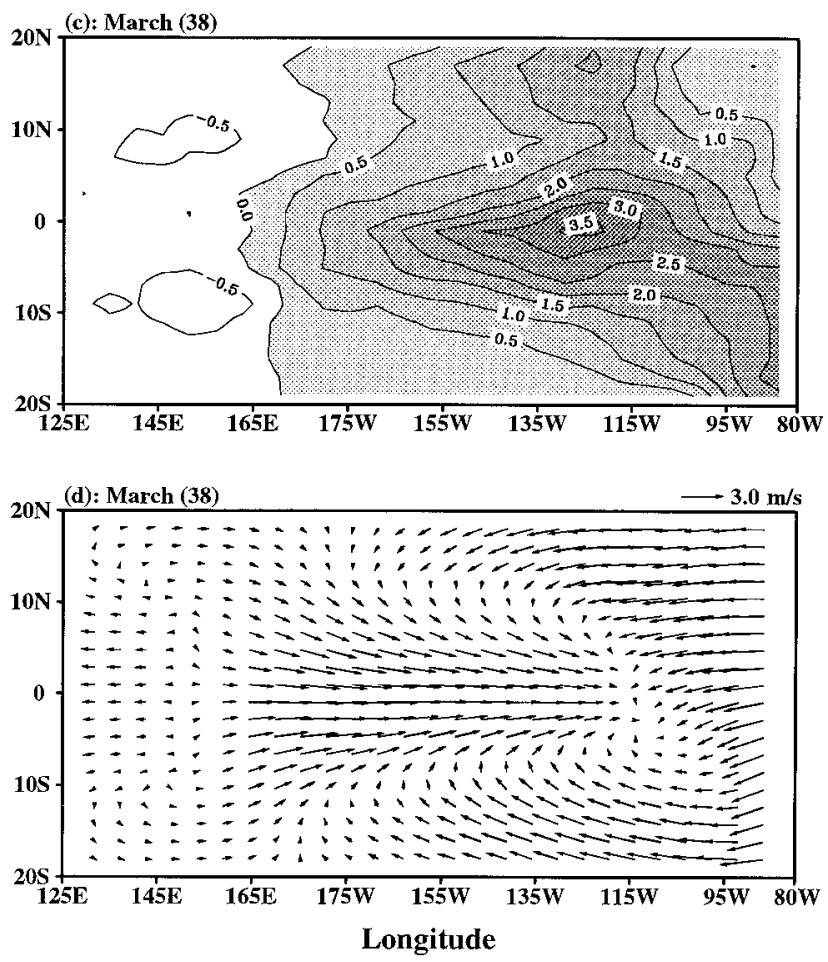

Figure 15. Comparison of the horizontal structures for the (a and c) SST and (b and d) surface wind anomalies between the (left) standard and (right) modified models for a warm El Niño event during March. 
The Standard Model

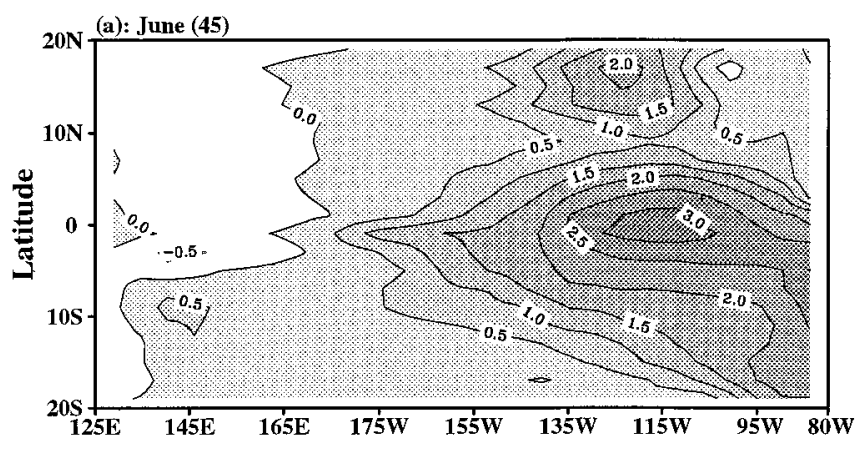

The Modified Model

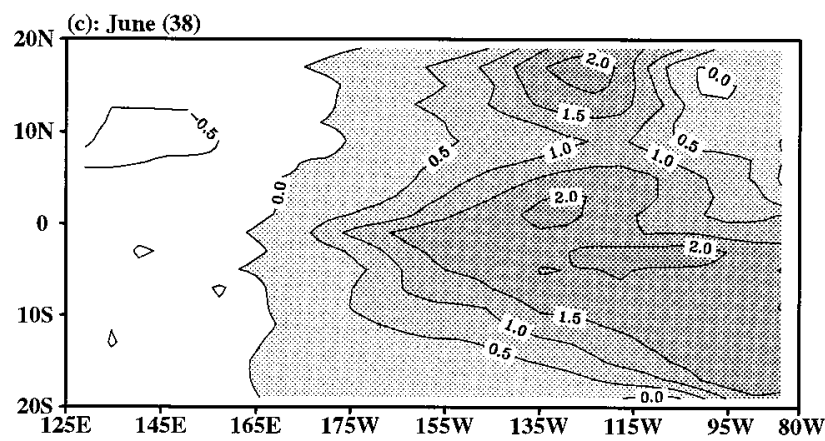

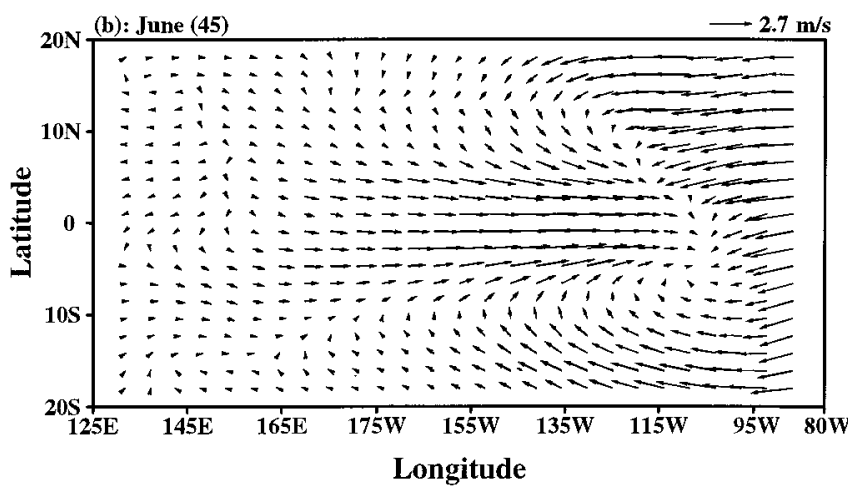

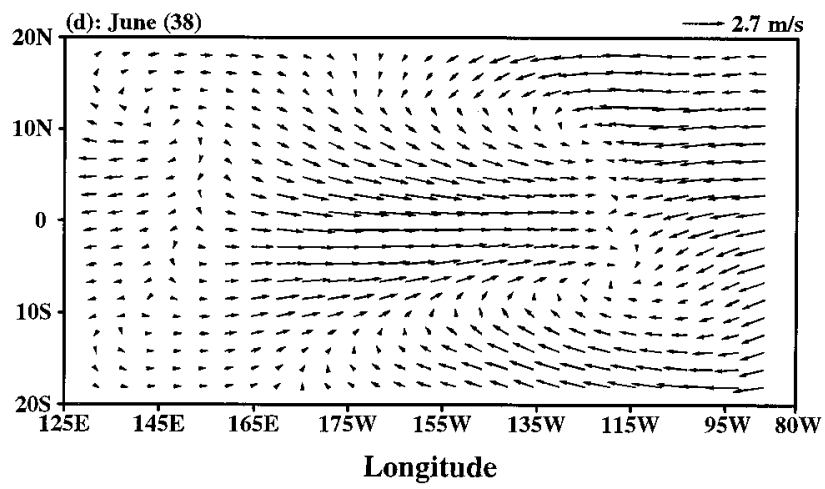

Figure 16. Comparison of the horizontal structures for the (a and c) SST and (b and d) surface wind anomalies between the (left) standard and (right) modified models for a warm El Niño event during June.

SST anomalies in both models have decreased. For the modified model, the off-equatorial western Pacific cold SST anomalies persist, as do their associated equatorial easterly winds over the far western Pacific. These patterns continue through June (Figure 16) as the El Niño warming further abates. Owing to the easterly wind anomalies over the western Pacific (with magnitudes of about half that of the westerly anomalies in the central Pacific) for the modified model, the El Niño warming in the east has now relaxed more relative to the standard model.

Along with the spatial evolution of a single event showing western Pacific interannual anomaly patterns in the modified model, time series for the full 100 years of the modified model integrations show that these patterns occur regularly throughout. Figures $17 \mathrm{a}$ and $17 \mathrm{~b}$ compare model SST anomalies in the Nino3 and Nino6 regions, and model zonal wind anomalies in the Nino4 and Nino5 regions, respectively. (Note that the standard ZC model does not show the western Pacific anomaly patterns, so SST and zonal wind anomalies between the western and eastern Pacific are not compared.) The model Nino6 and Nino3 SST anomalies vary nearly out of phase (with small lag), as do the model Nino5 and Nino4 zonal wind anomalies. These western Pacific SST and zonal wind anomaly behaviors are consistent with the observations shown in Figure 4. However, when compared with observations, the model's ability to simulate these western Pacific features is better during the warm phase than during the cold phase of ENSO for reasons discussed earlier.

We now examine what induces off-equatorial western Pacific SST anomalies in the coupled models. Figure 18 compares the model Nino6 SST anomaly variation with the vertical SST advection (associated with the wind stress curl and the anomalous vertical temperature gradient) for both the standard and modified models. The solid line represents $\partial T / \partial t+\alpha_{s} T$ and the dashed line represents $M\left(\bar{w}+w_{\text {curl }}\right) \partial T / \partial z$. The reason for plotting $\partial T / \partial t+\alpha_{s} T$ (rather than $\partial T / \partial t$ ) is that the thermal (or surface flux) damping term $-\alpha_{s} T$ shifts the phase of $\partial T / \partial t\left(90^{\circ}\right)$ in the calculation of the SST anomalies, so this phase shift should be considered for analyses of the model output. Vertical SST advection in the standard model is nearly zero (Figure 18a). The modified model produces off-equatorial western Pacific SST anomalies, equatorial zonal wind anomalies over the far western Pacific, and off-equatorial wind stress curl. As discussed earlier, off-equatorial thermocline displacement, being responsible for the variation of $\partial T / \partial z$ by the model parameterization, is also related to wind stress curl. Therefore the product of $M\left(\bar{w}+w_{\text {curl }}\right)$ and $\partial T / \partial z$ accounts for the Nino6 SST anomaly variation as shown in Figure $18 \mathrm{~b}$.

\section{Summary and Discussion}

During the warm phase of ENSO, the COADS and OLR data sets show that the warm SST and low SLP anomalies in the equatorial eastern Pacific and the low OLR anomalies in the equatorial central Pacific are accompanied by cold SST and high SLP anomalies in the off-equatorial western Pacific and high OLR anomalies in the off-equatorial far western Pacific. Similarly, equatorial westerly wind anomalies in the central Pacific are accompanied by equatorial easterly wind anomalies over the far western Pacific. The converse occurs during the cold phase of ENSO. Along with the eastern Pacific anomalies these accompanying western Pacific anomaly patterns are also robust features of ENSO, independent of data sets. It is argued that equatorial easterly (westerly) wind anomalies over the far western Pacific during the warm (cold) phase of ENSO are 

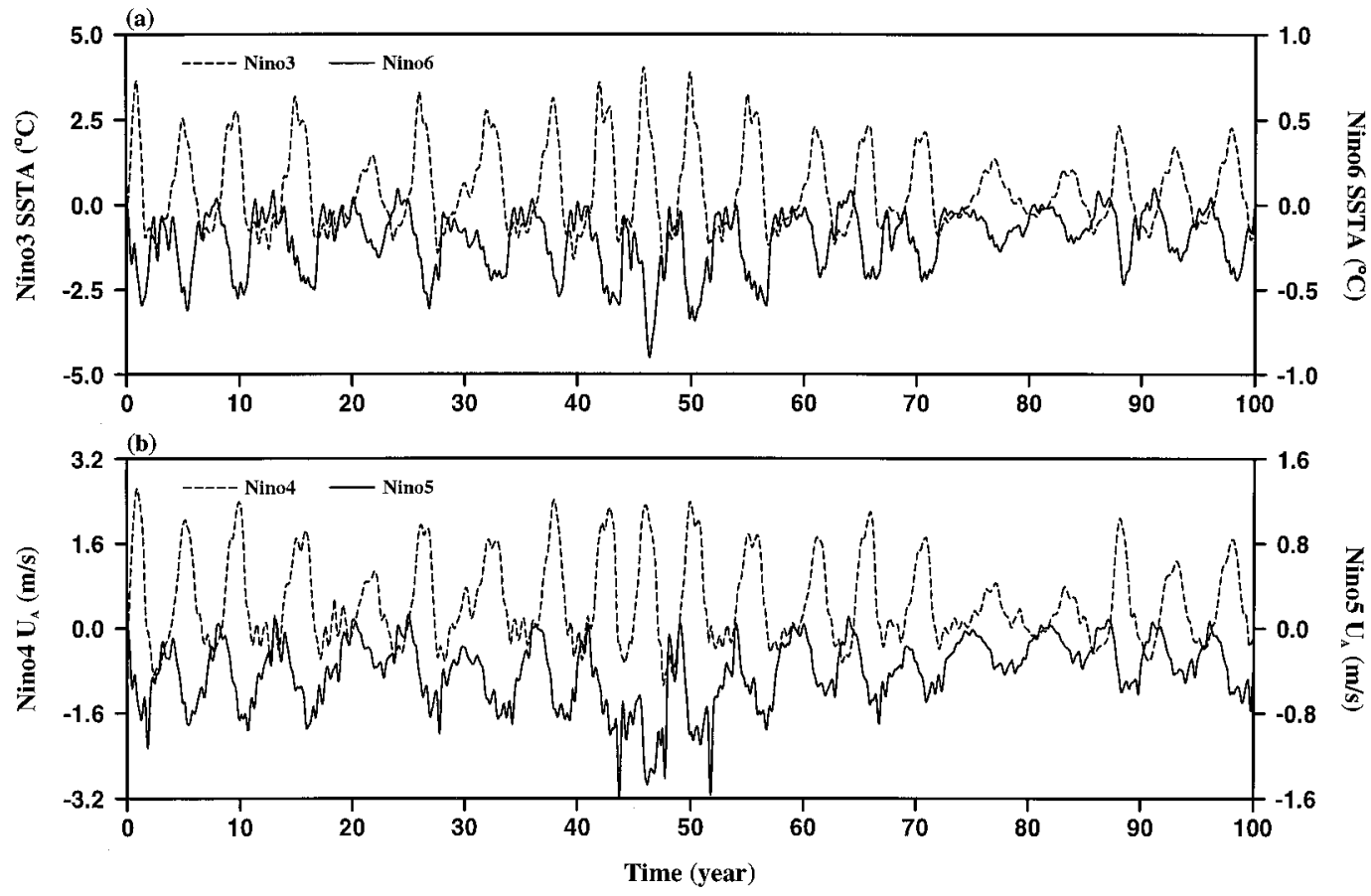

Figure 17. Three-month running means of the modeled (a) SST anomalies in the Nino3 (dashed line) and Nino6 (solid line) regions, and (b) the zonal wind anomalies in the Nino4 (dashed line) and Nino5 (solid line) regions, using the modified coupled $\mathrm{ZC}$ model.

initiated by off-equatorial western Pacific cold (warm) SST anomalies. These western Pacific equatorial westerly and easterly wind anomalies are important since they affect the evolution of ENSO [Wyrtki, 1975; McCreary, 1976; Busalacchi and O'Brien, 1981; Philander, 1981; Tang and Weisberg, 1984; Phi- lander, 1985]. The dynamical implications of these observed western Pacific patterns are explored in the preceding sections. Implementation of the Zebiak [1986] atmosphere model demonstrates that small-amplitude (compared to the east) offequatorial western Pacific cold (warm) SST anomalies are suf-
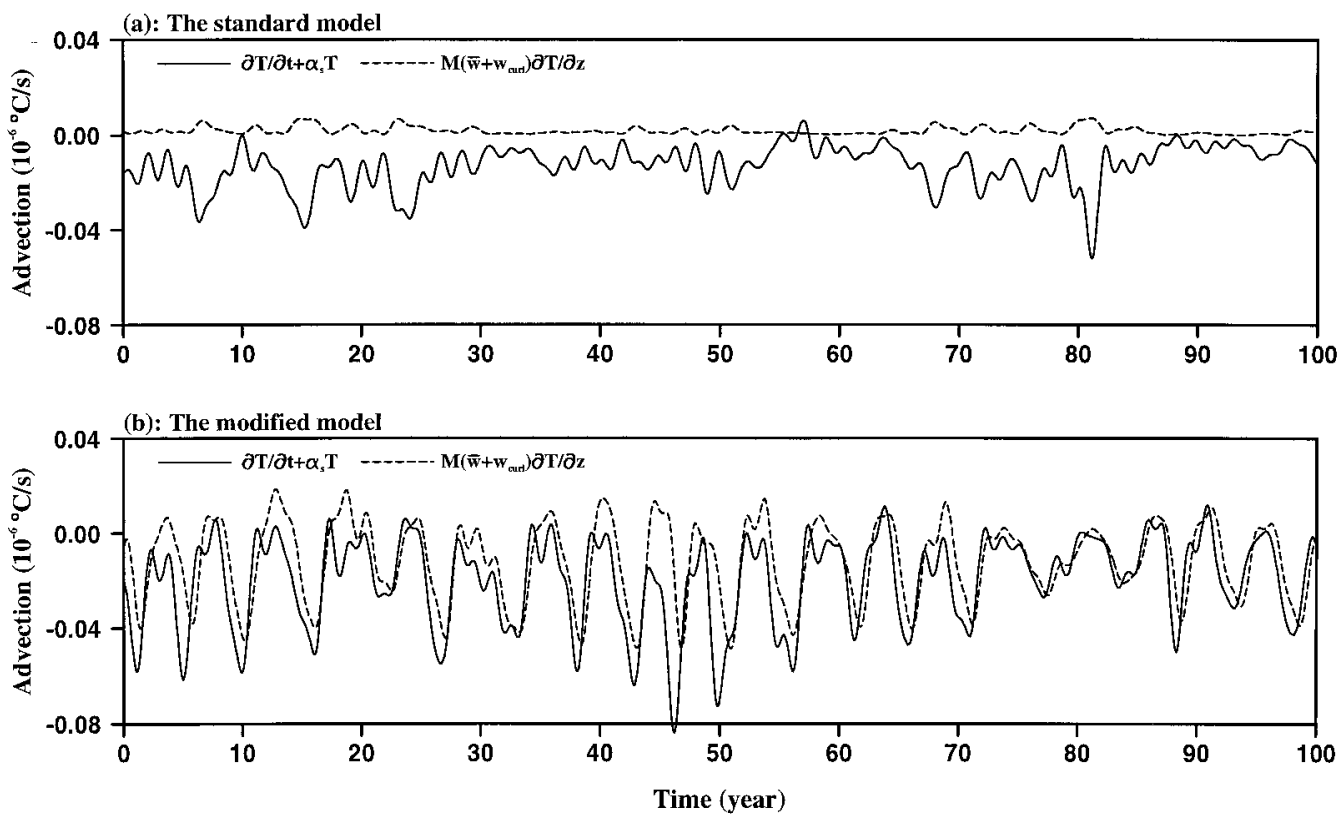

Figure 18. Comparisons between modeled time series of the Nino6 SST anomaly variations and the vertical SST advection associated with wind stress curl and anomalous vertical temperature gradient for (a) the standard model and (b) the modified model. The solid line represents $\partial T / \partial t+\alpha_{s} T$ and the dashed line represents $M\left(\bar{w}+w_{\text {curl }}\right) \partial T / \partial z$. All data are low-pass filtered to remove oscillations on timescales shorter than 18 months. 
ficient to produce equatorial easterly (westerly) winds over the far western Pacific during the warm (cold) phase of ENSO, owing to the low-level moisture convergence feedback process in the western Pacific. The mechanism of equatorial easterly wind initiation by off-equatorial western Pacific cold SST anomalies is then shown to be operant in a modified version of the coupled ocean-atmosphere ZC model.

In addition to the conventional ENSO indices, the western Pacific anomaly patterns suggest two new indices denoted by Nino5 (for zonal winds) and Nino6 (for SST or SLP). To the extent that western Pacific variability is important for ENSO, these new indices are useful for tracking the evolution of ENSO and for diagnosing the performance of ENSO-related models. The variability in the Nino5 and Nino6 indices shows strong correlation with the variability in the Nino3 and Nino4 indices. During the warm (cold) phase of ENSO, Nino3 warm (cold) SST and low (high) SLP anomalies are accompanied by Nino6 cold (warm) SST and high (low) SLP anomalies. Similarly, Nino4 westerly (easterly) wind anomalies are accompanied by Nino5 easterly (westerly) wind anomalies.

Zonal winds near the equator over the western Pacific can induce off-equatorial wind stress curl. As shown in section 4, anomalous vertical velocity in the off-equatorial regions is primarily controlled by wind stress curl and thermocline displacement, which is determined by both the local wind stress curl and the integrated effect of forced off-equatorial Rossby waves [Meyers, 1979; McCreary, 1980; Kessler, 1990]. Therefore the modification to the ZC model focused on the vertical SST advection associated with both the wind stress curl and the anomalous change in the vertical temperature gradient (parameterized in terms of thermocline displacement in the $\mathrm{ZC}$ model). This is consistent with the NCEP ocean model reanalysis discussed by Goddard and Graham [1997] wherein during the warm phase of ENSO western Pacific cold subsurface temperature anomalies can affect SST despite the mean thermocline being relatively deep there. Our argument that offequatorial wind stress curl produces off-equatorial SST anomalies is also compatible with the Meyers et al. [1986] finding that evaporation caused cold SST anomalies in the equatorial western Pacific during the 1982-1983 El Niño, since the wind stress curl effect is zero (see equation (4c)) and the zonal wind anomalies are large on the equator.

Based upon the available observations, can off-equatorial Ekman pumping provide a plausible mechanism for the observed interannual SST variations? Assuming a one-dimensional balance, the net heat flux required may be obtained from $\rho C_{p} h \partial T / \partial t=Q_{s}-Q_{-h}$, where $h$ is the mixed layer depth and $Q_{s}-Q_{-h}$ is the difference between the surface flux and the entrainment and penetrative fluxes at the base of the mixed layer. For an anomalous rate of change of SST in the vicinity of $12^{\circ} \mathrm{N}, 150^{\circ} \mathrm{E}$ amounting to about $1^{\circ} \mathrm{C}$ per year (from COADS) and a mean mixed layer depth of $80 \mathrm{~m}$ (from expendable bathythermograph (XBT) data provided by W. S. Kessler (personal communication, 1998)), the net heat flux requirement $\left(Q_{s}-Q_{-h}\right)$ is only about $10 \mathrm{~W} \mathrm{~m}^{-2}$. For the relatively large 1972-1973 and 1982-1983 El Niño events, the anomalous thermocline displacements, as evidenced by the $20^{\circ} \mathrm{C}$ isotherm depth, were in excess of $50 \mathrm{~m}$, and these displacements are consistent with local Ekman pumping and off-equatorial Rossby waves [e.g., Kessler, 1990] generated in the western Pacific. Parameterizing the heat flux at the base of the mixed layer by an entrainment velocity $w_{e}$ gives $Q_{-h}=\rho C_{p} w_{e} \Delta T$. Letting $\Delta T$ equal $8^{\circ} \mathrm{C}$ (the difference between the mixed layer temperature and the $20^{\circ} \mathrm{C}$ isotherm) and assuming that all of the cooling is by entrainment, the resulting $w_{e}$ amounts to about $3.0 \times 10^{-7} \mathrm{~m} \mathrm{~s}^{-1}$, which is an order of magnitude smaller than the vertical velocity due to local Ekman pumping. Noting further that the mixed layer at this location tends to be shallower preceding the peak El Niño (only about $40 \mathrm{~m}$ deep during fall 1982, for instance), thereby reducing the heat flux requirement, it may be concluded that ocean dynamics, via Ekman pumping and entrainment, can account for the offequatorial interannual SST variations. Confirming this experimentally is another matter, however, since the approximate 10 $\mathrm{W} \mathrm{m}^{-2}$ net (surface plus entrainment) heat flux requirement is within the error level of even the most accurate net surface flux measurements [e.g., Fairall et al., 1996].

The western Pacific oscillator paradigm of Weisberg and Wang [1997b] emphasizes the importance of off-equatorial SST and SLP variations west of the date line for initiating equatorial easterly winds over the far western Pacific. It is argued that these easterly winds compete with westerly winds in the central Pacific, providing a negative feedback to enable the coupled ocean-atmosphere system to oscillate. It is plausible that both the delayed oscillator [Suarez and Schopf, 1988; Battisti and Hirst, 1989] and the western Pacific oscillator may be operant in nature. In both mechanisms, local oceanatmosphere positive feedbacks occur in the equatorial eastern or central Pacific regions. However, the negative feedbacks of the two mechanisms are different. In the delayed oscillator mechanism, negative feedback results from the equatorial eastern Pacific region. Free Rossby waves generated there propagate westward and reflect from the western boundary as Kelvin waves, providing a negative feedback for the coupled oceanatmosphere system to oscillate. In the western Pacific oscillator mechanism, negative feedback comes directly from the western Pacific. Equatorial easterly winds over the far western Pacific, which are initiated by off-equatorial western Pacific cold SST anomalies, produce ocean upwelling Kelvin waves that propagate eastward along the equator to provide a negative feedback. Such upwelling response in the equatorial eastern Pacific caused by easterly winds in the far western Pacific was demonstrated by Tang and Weisberg [1984] and Philander [1985].

Although the coupled ZC model as modified here shows off-equatorial western Pacific cold SST anomalies and equatorial easterly wind anomalies over the far western Pacific during the warm phase of ENSO, it underrepresents these western Pacific anomaly patterns during the cold phase of ENSO. This may be due to the fact that the ZC model favors the warm phase of ENSO. Two factors that may limit the cold phase simulation of ENSO are (1) the Zebiak [1986] version of the Gill [1980] atmospheric model and (2) the asymmetric parameterization in the subsurface temperature anomaly in (6). The Zebiak [1986] atmospheric response to positive SST anomaly is larger than the response to negative SST anomaly in the equatorial eastern Pacific, due to the convergence feedback in the heating parameterization. The subsurface temperature anomaly parameterization is more sensitive to a positive thermocline displacement anomaly than to a negative thermocline displacement anomaly. These two factors contribute to an asymmetric model ENSO, favoring simulation of the warm phase. For a better simulation of equatorial westerly winds over the far western Pacific and off-equatorial western Pacific warm SST anomalies during the cold phase of ENSO, the problem of the asymmetric oscillation in the coupled model must first be solved. Dewitte and Perigaud [1996] showed that more symmet- 
ric model oscillations can be obtained in an uncoupled $\mathrm{ZC}$ ocean model by specifying a symmetric sensitivity for the subsurface temperature anomaly in relation to the thermocline displacement anomaly. Further work on this topic is needed.

The fetch of the equatorial easterly wind anomalies produced over the western Pacific during the model warm phase of ENSO is also underrepresented when compared with observations. As observed in nature, once initiated over the far western Pacific by off-equatorial SST variations, equatorial easterly wind anomalies expand eastward to cover the entire equatorial western Pacific region as the El Niño abates. The modified coupled model does not produce this feature. Also observed after equatorial easterly winds form over the far western $\mathrm{Pa}$ cific is a pattern of SST warming and atmosphere convergence over the Indonesian archipelago, which may account for further development of easterly winds. With the western boundary of the coupled model at $129^{\circ} \mathrm{E}$, these observed behaviors are not included. Also, the standard ZC model includes an equatorial mean thermocline throughout its domain, and our modified version adds an idealized symmetric meridional structure to the western Pacific domain. More realistic geometry and thermocline climatology may be important for improving upon simulations of interannual variability in the tropical Pacific.

It is important to recognize that the small modification that we made to the ZC model produces a similarly small modification to the total model behavior. The primary mechanism of the ZC model, as analyzed by Battisti and Hirst [1989] to be the delayed oscillator mechanism, is therefore not materially altered by our western Pacific subsurface temperature anomaly parameterization modification. Given the modified model shortcomings, particularly the failure of the easterly wind anomalies in the far western Pacific to grow in fetch and magnitude as observed in nature, there is little justification for quantitative comparisons between the delayed oscillator and the western Pacific oscillator mechanisms using this model. What the modified model experiment suggests, however, is that both mechanisms may coexist within the context of a coupled ocean-atmosphere system.

It is also known that the $\mathrm{ZC}$ model does not simulate offequatorial wind anomalies in the eastern Pacific very well (see Figures 13-16, Zebiak [1986], and Zebiak and Cane [1987]). This is primarily a consequence of the Gill-type atmosphere model that responds in the form of an atmospheric Kelvin wave characterized by easterly flows of relatively large meridional extent to the east of a heat source [Gill, 1980]. Here, we emphasized equatorial zonal wind anomalies in the western Pacific and related these to off-equatorial thermocline anomalies there that are controlled by both the local wind stress curl and the integrated effect of forced off-equatorial Rossby waves [Meyers, 1979; McCreary, 1980; Kessler, 1990]. In nature the integrated effect of the off-equatorial Rossby waves appears to emanate largely from the western half of the Pacific, while in the $\mathrm{ZC}$ model the eastern Pacific also plays a role for the reason given above. This is another model shortcoming that argues against additional quantitative comparisons between mechanisms. However, when comparing off-equatorial eastern Pacific wind stress curl in both the standard and the modified models, the results are similar as contrasted with the western Pacific patterns that only occur within the modified model. The western Pacific patterns are therefore a consequence of western Pacific processes, albeit impacted by unrealistic model wind stress curl in the off-equatorial eastern Pacific.
In summary, the paper provides both observational and numerical modeling studies focusing on western Pacific variability in relation to ENSO. Observations suggest the introduction of two new western Pacific indices, one for off-equatorial SST or SLP and the other for equatorial winds, that covary with the conventional ENSO indices in the central and eastern Pacific. Equatorial western Pacific winds are argued as being important for coupled ocean-atmosphere system oscillations. An atmosphere model shows that the observed small off-equatorial western Pacific SST anomalies are sufficient to produce equatorial zonal wind reversals over the far western Pacific. A coupled ocean-atmosphere model shows that co-oscillating western and eastern Pacific anomaly patterns consistent with observations can be produced in the context of a coupled ocean-atmosphere system. Given recognized shortcomings in both the ocean and the atmosphere models, further model improvements are necessary to achieve quantitative assessments on the relative roles that different mechanisms play in ENSO.

Acknowledgments. This work is supported by the National Oceanic and Atmospheric Administration, Office of Global Programs, grant NA66GPO119 and by the National Science Foundation, Division of Ocean Sciences, grant OCE-9525912. We thank S. Zebiak and M. Cane for providing their coupled ocean-atmosphere model code and for their comments on the manuscript. D. Mayer, NOAA/AOML, provided the COADS anomaly data and many helpful discussions during the course of our collaborative studies. J. Janowiak at NOAA/ NCEP and W. Kessler at NOAA/PMEL provided the OLR and the historical XBT data, respectively.

\section{References}

Battisti, D. S., and A. C. Hirst, Interannual variability in the tropical atmosphere-ocean model: Influence of the basic state, ocean geometry and nonlinearity, J. Atmos. Sci., 45, 1687-1712, 1989.

Busalacchi, A., and J. J. O'Brien, Interannual variability of the equatorial Pacific in the 1960s, J. Geophys. Res., 86, 10,901-10,907, 1981.

Colin, C., C. Henin, P. Hisard, and C. Oudot, Le Courant de Cromwell dans le Pacifique central en fevrier, Cah. ORSTOM Ser. Oceanogr., 9, 167-186, 1971.

Deser, C., and J. M. Wallace, Large-scale atmospheric circulation features of warm and cold episodes in the tropical Pacific, J. Clim., 3, 1254-1281, 1990.

Dewitte, B., and C. Perigaud, El Niño-La Niña events simulated with Cane and Zebiak's model and observed with satellite or in situ data, II, Model forced with observations, J. Clim., 9, 1188-1207, 1996.

Fairall, C. W., E. F. Bradley, D. P. Rogers, J. B., Edson, and G. S. Young, Bulk parameterization of air-sea fluxes for Tropical Ocean Global Atmosphere Coupled Ocean Atmosphere Response Experiment, J. Geophys. Res., 101, 3747-3764, 1996.

Gill, A. E., Some simple solutions for heat-induced tropical circulation. Q. J. R. Meteorol. Soc., 106, 447-462, 1980.

Goddard, L., and N. E. Graham, El Niño in the 1990s, J. Geophys. Res., 102, 10,423-10,436, 1997.

Kessler, W. S., Observations of long Rossby waves in the northern tropical Pacific, J. Geophys. Res., 95, 5183-5219, 1990.

Mayer, D. A., and R. H. Weisberg, El Niño-Southern Oscillationrelated ocean-atmosphere coupling in the western equatorial Pacific, J. Geophys. Res., 103, 18,635-18,648, 1998.

McCreary, J. P., Eastern tropical ocean response to changing wind systems: With applications to El Niño, J. Phys. Oceanogr., 6, 632645, 1976.

McCreary, J. P., Modeling wind-driven ocean circulation, Tech. Rep. HIG-80-3, 64 pp., Hawaii Inst. Geophys., Honolulu, 1980.

McCreary, J. P., and D. L. T. Anderson, An overview of coupled ocean-atmosphere models of El Niño and the Southern Oscillation, J. Geophys. Res., 96, 3125-3150, 1991.

Meyers, G., On the annual Rossby wave in the tropical North Pacific Ocean, J. Phys. Oceanogr., 9, 663-674, 1979.

Meyers, G., J. R. Donguy, and R. K. Reed, Evaporative cooling of the 
western equatorial Pacific Ocean by anomalous winds, Nature, 323, 523-526, 1986.

Neelin, J. D., M. Latif, and F.-F. Jin, Dynamics of coupled oceanatmosphere models: The tropical problem, Annu. Rev. Fluid Mech., 26, 617-659, 1994.

Neelin, J. D., D. S. Battisti, A. C. Hirst, F.-F. Jin, Y. Wakata, T. Yamagata, S. E. Zebiak, ENSO theory, J. Geophys. Res., 103, 14,262-14,290, 1998.

Philander, S. G., The response of equatorial oceans to a relaxation of the trade winds, J. Phys. Oceanogr., 11, 176-189, 1981.

Philander, S. G., El Niño and La Niña, J. Atmos. Sci., 42, 2652-2662, 1985.

Philander, S. G., El Niño, La Niña, and the Southern Oscillation, 289 pp., Academic, San Diego, Calif., 1990.

Rasmusson, E. M., and T. H. Carpenter, Variations in tropical sea surface temperature and surface wind fields associated with the Southern Oscillation/El Niño, Mon. Weather Rev., 110, 354-384, 1982.

Rasmusson, E. M., and J. M. Wallace, Meteorological aspects of the El Niño/Southern Oscillation, Science, 222, 1195-1202, 1983.

Sciremammano, F., A suggestion for the presentation of correlations and their significance levels, J. Phys. Oceanogr., 9, 1273-1276, 1979.

Smith, T. M., R. W. Reynolds, R. E. Livezey, and D. C. Stokes, Reconstruction of historical sea surface temperature using empirical orthogonal functions, J. Clim., 9, 1403-1420, 1996.

Suarez, M. J., and P. S. Schopf, A delayed action oscillator for ENSO, J. Atmos. Sci., 45, 3283-3287, 1988.

Tang, T. Y., and R. H. Weisberg, On the equatorial Pacific response to the 1982/1983 El Niño-Southern Oscillation event, J. Mar. Res., 42, 809-829, 1984 .

Weisberg, R. H., and C. Wang, Slow variability in the equatorial west-central Pacific in relation to ENSO, J. Clim., 10, 1998-2017, 1997a.

Weisberg, R. H., and C. Wang, A western Pacific oscillator paradigm for the El Niño-Southern Oscillation, Geophys. Res. Lett., 24, 779782, $1997 \mathrm{~b}$.

Woodruff, S. D., R. J. Slutz, R. L. Jenne, and P. M. Steurer, A comprehensive ocean-atmosphere data set, Bull. Am. Meteorol. Soc., 68, 1239-1250, 1987.

Wyrtki, K., El Niño-The dynamic response of the equatorial Pacific Ocean to atmospheric forcing, J. Phys. Oceanogr., 5, 572-584, 1975.

Zebiak, S. E., Atmospheric convergence feedback in a simple model for El Niño, Mon. Weather Rev., 114, 1263-1271, 1986.

Zebiak, S. E., Diagnostic studies of Pacific surface winds, J. Clim., 3, 1016-1031, 1990.

Zebiak, S. E., and M. A. Cane, A model El Niño-Southern Oscillation, Mon. Weather Rev., 115, 2262-2278, 1987.

J. I. Virmani, C. Wang, and R. H. Weisberg, Department of Marine Science, University of South Florida, 140 Seventh Avenue South, St. Petersburg, FL 33701. (e-mail: wang@ocg6.marine.usf.edu)

(Received December 3, 1997; revised October 16, 1998; accepted November 17, 1998.) 
